\title{
Acanthaceae da Marambaia, Estado do Rio de Janeiro, Brasil
}

\author{
Denise Monte Braz ${ }^{1,2}$ e Igor Henrique Freitas Azevedo ${ }^{1}$
}

Recebido: 23.02.2016; aceito: 3.08.2016

\begin{abstract}
Acanthaceae of Marambaia, State of Rio de Janeiro, Brazil). This work consists of the taxonomic treatment of the Acanthaceae Juss. in Marambaia, State of Rio de Janeiro, Brazil, and their distribution in the different local plant communities. Five genera and nine species were found in mangrove, sand coastal plains (restingas), rain forest, and in urban areas. Thunbergia alata is introduced and widely naturalized throughout Brazil, and Ruellia blechum is a neotropical species also naturalized; the other species are native: Avicennia schaueriana, Aphelandra longiflora, Justicia brasiliana, J. cydoniifolia, J. plumbaginifolia, Ruellia solitaria, and Schaueria litoralis. Keys to species, descriptions, illustrations, comments on taxonomy, and their distribution in the local plant communities, in other restingas in Rio de Janeiro State, and in Brazil are provided. The species of Acanthaceae in Marambaia are important resources for different groups of pollinators and include typical (Justicia brasiliana, J. cydoniifolia) and exclusive (Schaueria litoralis) species of the restinga; these species plus Avicennia schaueriana are threatened in Rio de Janeiro State.
\end{abstract}

Keywords: Atlantic forest, mangrove, sand coastal plains, taxonomy, threatened species

RESUMO - (Acanthaceae da Marambaia, Estado do Rio de Janeiro, Brasil). Este trabalho consiste do tratamento taxonômico das Acanthaceae Juss. na Marambaia, Estado do Rio de Janeiro, e sua distribuição nas diferentes formações vegetais locais. Foram constatados cinco gêneros e nove espécies encontradas nos manguezais, na restinga e na floresta ombrófila, além de áreas urbanizadas. Thunbergia alata é introduzida e amplamente naturalizada no Brasil inteiro e Ruellia blechum é uma espécie neotropical também naturalizada; as demais espécies (Avicennia schaueriana, Aphelandra longiflora, Justicia brasiliana, J. cydoniifolia, J. plumbaginifolia, Ruellia solitaria e Schaueria litoralis) são nativas. São apresentadas chave de identificação, descrições, ilustrações, comentários taxonômicos e a ocorrência nas formações vegetais locais, em outras restingas fluminenses e no Brasil. As espécies de Acanthaceae da Marambaia são recursos importantes para diferentes grupos de polinizadores e reúnem espécies típicas (Justicia brasiliana, J. cydoniifolia) e exclusivas (Schaneria litoralis) das restingas; essas espécies, juntamente com Avicennia schaueriana, são ameaçadas de extinção na flora fluminense.

Palavras-chave: espécies ameaçadas, Floresta Atlântica, manguezal, restinga, taxonomia

\section{Introdução}

As Acanthaceae reúnem cerca de 200 gêneros e pelo menos 4000 espécies, estando dentre as dez famílias mais numerosas das plantas com flores (McDade et al. 2008, Tripp \& McDade 2014, Daniel $\&$ McDade 2014). Exceto pela beleza de algumas espécies ornamentais (Lorenzi \& Souza 2008, Sartin et al. 2014, Tripp \& McDade 2014), em função da grande variação morfológica e de classificações baseadas em aspectos de difícil reconhecimento, foram pouco estudadas no século passado. Atualmente, o entendimento da família tem se tornado conciso e sua sistemática elucidada com base na filogenia molecular (e.g., Schwarzbach \& McDade 2002, McDade et al. 2005, 2008, 2012, Borg et al. 2008, Daniel \& McDade 2014, entre outros) e na taxonomia formal (e.g., Wasshausen 1995, Wasshausen \& Wood 2004, Scotland \& Vollesen 2000, Ezcurra 1993, 2002, Kameyama 2008). O sistema de Scotland \& Vollesen (2000) permitiu um entendimento dos táxons infrafamiliares e tratou as Acanthaceae reunidas nas três subfamílias Nelsonioideae, Thunbergioideae e Acanthoideae. Avicennia L., com suas espécies típicas dos manguezais no mundo todo, forma com as demais Thunbergioideae um grupo natural fortemente sustentado (Schwarzbach \& McDade 2002, McDade et al. 2008, Borg et al. 2008).

1. Universidade Federal Rural do Rio de Janeiro, Instituto de Ciências Biológicas e da Saúde, Departamento de Botânica, BR-465, $\mathrm{Km}$ 7, 23890-000, Seropédica, RJ

2. Autor para correspondência: dmbraz@ufrrj.br 
As variações na morfologia do fruto são evidências que auxiliam na caracterização das subfamílias e refletem a filogenia atualmente aceita para as Acanthaceae. O tipo de fruto básico na família é uma cápsula loculicida bivalva, originada de um gineceu bicarpelar, com sementes em placentação axial (Barroso et al. 1999, Borg et al. 2008, McDade et al. 2008, 2012), em geral com forma alongada (i.e., com comprimento pelo menos duas vezes a largura), subcilíndrica, fusiforme, ovóide ou claviforme. A cápsula loculicida enrijecida e com deiscência explosiva apontada como sinapomorfia para a família (McDade et al. 2008, 2012, Stevens 2015) é observada nos grupos basais (Nelsonioideae e Thunbergioideae), tendo sofrido variações pontuais (autapomorfias) para uma cápsula carnosa diferenciada em Avicennia e uma forma drupóide em Mendoncia (Borg et al. 2008, McDade et al. 2012); nas Acanthoideae, o grupo mais derivado e representativo, o funículo se modificou em estrutura alongada, curva e afilada na extremidade, o retináculo, que auxilia e direciona na expulsão das sementes no momento da abertura da Cápsula (Witztum \& Schulgasser 1995).

Leonard (1951) já havia indicado a América do Sul como um dos centros de diversidade das Acanthaceae e Wasshausen \& Wood (2004) confirmaram aproximadamente metade de seus representantes nos neotrópicos ( 85 gêneros e 2.000 espécies). Na flora brasileira constam 41 gêneros e 449 espécies de Acanthaceae (Profice et al. 2015), ocorrendo naturalmente em praticamente todos os tipos de vegetação, mas sempre em áreas com elevado grau de preservação. Para o Rio de Janeiro são reconhecidos 22 gêneros e 94 espécies (Profice et al. 2015) e os tratamentos mais detalhados se restringem ao estudo de floras locais na APA Cairuçú, em Paraty, na Reserva de Rio das Pedras, em Mangaratiba, e na Reserva Ecológica de Macaé de Cima, em Nova Friburgo (Profice 1997, 1998, 2013).

Floras locais no Brasil têm se mostrado como uma importante ferramenta no conhecimento da família, auxiliando no esclarecimento de diversas questões taxonômicas e nomenclaturais, tais como sinonimizações, ampliação de áreas de ocorrência e retificação de diagnoses (Wasshausen \& Smith 1969, Wasshausen 1992, 1998, Wasshausen \& Harvey 1995 , Kameyama 1995, Profice 1997, 1998, Braz et al. 2002), entre outros aspectos que os tornam referências atemporais para os táxons estudados. As numerosas espécies descritas somente na última década para a América do Sul e para o Brasil (Kameyama 2008,
Braz \& Monteiro 2006, Côrtes \& Rapini 2011, Wood 2012, Indriuna \& Kameyama 2012, Wasshausen 2013, entre muitos outros) atestam a necessidade de novos estudos com a família. Para McDade et al. (2008) ainda é esperado um aumento nesses números.

A Marambaia reúne formações vegetais distintas em uma área relativamente isolada, limitada pelo mar, incluindo manguezal, diferentes formações de restinga e a floresta ombrófila. A flora vascular local é rica e uma listagem geral apontou 123 famílias botânicas, reunindo 615 espécies, sendo 569 de Angiospermas (Conde et al. 2005). Estudos posteriores com grupos taxonômicos específicos têm elevado esses números consideravelmente (e.g., Myrtaceae, Souza et al. 2007; Rubiaceae, Hottz et al. 2007; Sapindaceae, Somner et al. 2009; Poaceae, Silva et al. 2012; Anacardiaceae e Meliaceae, Corrêa \& Freire 2010). A flora da Marambaia vem sendo investigada pelo Departamento de Botânica da Universidade Federal Rural do Rio de Janeiro há mais de uma década e a coleção contida no Herbário RBR dessa Universidade também vem subsidiando investigações de outros aspectos da vegetação (Afonso et al. 2007, Menezes et al. 2010, Pimentel et al. 2011, Nettesheim et al. 2012, Pinto et al. 2010).

O presente estudo consiste no tratamento taxonômico das espécies nativas de Acanthaceae Juss. da Marambaia, contendo chave de identificação para as espécies, descrições, ilustrações, comentários diagnósticos, fenológicos e sobre o uso das espécies e notas sobre os gêneros. Além das formações vegetais locais, também são fornecidas a ocorrência no Brasil e em outras restingas fluminenses, adicionando conhecimentos da família especialmente na Floresta Atlântica e no Estado do Rio de Janeiro.

\section{Material e métodos}

Área de Estudo - A Marambaia está situada em parte dos Municípios do Rio de Janeiro, Itaguaí e Mangaratiba, entre as coordenadas $23^{\circ} 02^{\prime}$ a $23^{\circ} 06^{\prime} \mathrm{S}$ e $43^{\circ} 45^{\prime}$ a $43^{\circ} 54^{\prime} \mathrm{W}$ (Góes et al. 2005), na região denominada Costa Verde, que acompanha o litoral sul do Estado até São Paulo. Compreende uma faixa arenosa, denominada Restinga, cuja extremidade apoia-se numa porção montanhosa, conhecida por Ilha da Marambaia, com sua face norte voltada para a Baía de Sepetiba e a face sul banhada pelo Oceano Atlântico (Roncarati \& Menezes 2005). O macroclima é do tipo Aw - Clima Tropical Chuvoso (Mattos 2005) e o clima é ameno, com temperatura média anual de 
$23,6^{\circ} \mathrm{C}$ e precipitação média anual de $1.027,2 \mathrm{~mm}$, sendo março o mês mais chuvoso e agosto o mais seco (Menezes \& Araujo 1999). Além de integrar a APA Mangaratiba, a Marambaia é ocupada pelas Forças Armadas Brasileiras, que detêm o controle da área e impede a especulação imobiliária, intensa no litoral sul fluminense. Favorecida tanto pela posição geográfica, quanto pelo acesso restrito, a Marambaia conserva preservados trechos de vegetação natural. Na região da Ilha a vegetação é a floresta atlântica ombrófila de encosta e nas áreas de restinga são verificadas formações distintas e características, com vegetação aberta ou fechada, e em geral dominadas por plantas herbáceas, arbustivas ou arbóreas (Menezes \& Araújo 2005). Estudos detalhados sobre a geologia e outros aspectos físico e ambientais da Marambaia estão disponíveis em Menezes et al. (2005).

Tratamento Botânico - Foram realizadas expedições à área de estudo para coleta e observação de espécies entre os anos de 2007 a 2012. O material botânico, após o devido tratamento foi incorporado ao Herbário do Departamento de Botânica (RBR), da Universidade Federal Rural do Rio de Janeiro. Esse Herbário também contém as coletas realizadas durante os quase 10 anos de estudo na Marambaia, que serviram intensamente ao estudo.

O trabalho de laboratório incluiu a análise minuciosa da morfologia externa dos indivíduos e a identificação dos táxons se deu através de bibliografia especializada, comparação com coleções de outros herbários do Estado do Rio de Janeiro e consulta aos tipos nomenclaturais disponíveis na rede. A descrição morfológica seguiu os aspectos e as definições contidas em Radford et al. (1974) e Stearn (1998), além da bibliografia específica para a família, em especial, Wasshausen (1995), Wasshausen \& Wood (2003, 2004), Scotland \& Vollesen (2000) e Ezcurra (1993, 2002). Adistribuição das espécies foi verificada através da consulta de coleções de outros herbários fluminenses (GUA, RB) e da bibliografia específica. Para a caracterização das formações de restinga da Marambaia foi utilizada a classificação de Menezes \& Araújo (2005) e para as demais formações aquelas utilizadas por Menezes et al. (2005).

\section{Resultados e Discussão}

A maioria das Acanthaceae da Marambaia são da subfamília Acanthoideae, representadas por plantas subarbustivas (Justicia cydoniifolia (Nees) Lindau, $J$. brasiliana Roth, J. plumbaginifolia J.Jacq., Schaueria litoralis (Vell.) A.L.A.Côrtes, Aphelandra longiflora (Lindl.) Profice) ou herbáceas (Ruellia blechum L. e $R$. solitaria Vell.) (tabela 1). Dentre as Thunbergioideae, Thunbergia alata Poir é uma trepadeira, e o gênero Avicennia, típico dos manguezais, é representado pela espécie arbórea A. schaueriana Stapf \& Leechm. ex Moldenke.

O gênero Thunbergia é natural do velho mundo e reúne algumas espécies ornamentais (em geral T. alata, T. grandiflora, $T$. fragrans, $T$. ereta e T. mysorensis). T. alata Poir (figura 5a) é uma planta trepadeira que ocorre predominantemente como invasora na borda da floresta em contato com a área urbanizada. Suas flores são acompanhadas por um par de bractéolas bem desenvolvidas que cobrem o botão floral e parcialmente a corola, com o cálice inconspícuo, vestigial, anelar, e flores com corola amarela e mácula arroxeada na região da garganta. Uma vez que não é nativa ou neotropical e possivelmente se expandiu de cultivo como ornamental, T. alata não foi incluída no tratamento taxonômico.

Foram registradas quatro outras Acanthaceae além daquelas listadas inicialmente por Conde et al. (2005), somando nove espécies encontradas na floresta, no manguezal e na restinga (tabela 1). Ruellia blechum e Thunbergia alata ocorrem em áreas urbanas e/ou no entorno da floresta, enquanto que Avicennia schaueriana é típica do manguezal. Justicia brasiliana, J. cydoniifolia e Schaueria litoralis são restritas a formações de restinga na Marambaia e também ocorrem em outras restingas fluminenses. As demais, Aphelandra longiflora, J. plumbaginifolia e Ruellia solitaria, são típicas da floresta atlântica e na Marambaia ocorrem na floresta de encosta. Como esperado, Justicia L. e Ruellia L. são os gêneros mais ricos, com três e duas espécies, respectivamente, e os demais (Avicennia L., Aphelandra R.Br. e Schaueria Nees) com uma espécie cada.

As Acanthaceae são elementos comuns no subbosque de vegetações tropicais (Tripp \& McDade 2014, McDade 2008), sendo importantes elementos na manutenção da fauna polinizadora por reunir espécies exclusivamente polinizadas por animais (zoófilas) (Judd et al. 2008, McDade 2008). Além de ocuparem diferentes substratos, a enorme variedade de formas, cores e dimensões das flores e inflorescências permite uma vasta gama de polinizadores e uma revisão sobre os visitantes das flores de Acanthaceae é apresentada por Matias \& Consolaro (2015). Dentre as Acanthaceae da Marambaia, as formas das corola (figura 1) sugerem diferentes visitantes florais e associações com a fauna 
polinizadora já foram verificadas nas espécies e gêneros Avicennia schaueriana (Nadia et al. 2013), Aphelandra (Geissomeria spp.) (Pereira \& Sazima 1998, Braz et al. 2000, Faria \& Araujo 2010, Mathias \& Consolaro 2014), Justicia spp. (Pereira \& Sazima 1998, Braz et al. 2000, Faria \& Araujo 2010) e J. brasiliana (Braga et al. 2010), Ruellia spp. (Braz et al. 2000, Sigrist \& Sazima 202, Faria \& Araújo 2010, Vogel et al. 2004) e Thunbergia sp. (Migliorini et al. 2009).

Profice $(1997,2013)$ registrou J. plumbaginifolia e Aphelandra longiflora e outras 24 espécies de Acanthaceae ao estudar a floresta atlântica do continente nas proximidades da Marambaia. Justicia cydoniifolia, J. brasiliana e Schaueria litoralis são novos registros para a região da Costa Verde e a diversidade de espécies aponta essa como uma região de reconhecida riqueza da família no Estado.

Avicennia schaueriana, Justicia brasiliana, J. cydoniifolia e Schaueria litoralis estão listadas como ameaçadas na flora fluminense na categoria Vulnerável (tabela 1), enquanto que Aphelandra longiflora, Justicia plumbaginifolia, Ruellia solitaria como de Menor Preocupação (Baumgratz 2015). Por sua vez, Ruellia solitaria e Justicia cydoniifolia são espécies indicadoras do estágio clímax da vegetação herbácea e subarbustiva da restinga (CONAMA 2012). O registro dessas espécies atesta as boas condições da vegetação local e reitera a necessidade de sua preservação como banco de plantas típicas das formações de restinga e da Floresta Atlântica no Rio de Janeiro.

\section{Tratamento taxonômico}

\section{Acanthaceae Juss.}

Árvores, subarbustos com ramos escandentes, ervas eretas, raramente trepadeiras. Folhas simples, opostas, decussadas, sem estípulas, comumente com cistólitos. Inflorescências variadas, raramente flores solitárias; geralmente 1 bráctea e 2 bractéolas, estas às vezes encobrindo o botão e parte da corola. Flores hermafroditas, zigomorfas; segmentos do cálice geralmente 5, às vezes 4 , livres ou concrescidos entre si, (cálice vestigial, geralmente anelar em Thunbergia); corola gamopétala, zigomorfa, pentâmera, às vezes falsamente tetrâmera com os 2 lobos posteriores unidos, tubulosa, subinfundibuliforme, bilabiada, tubo basal geralmente bem delimitado; estames epipétalos, 4 geralmente didínamos, livres ou unidos dois a dois, ou 2 estames, às vezes 1-2 estaminódios, anteras 1-2-tecas, com ou sem projeções, geralmente rimosas (poricidas em Thunbergia); disco nectarífero anelar a cupular na base do ovário, ovário súpero, 2-carpelar, geralmente 2-locular, 2-10 óvulos por lóculo, superpostos, placentação axilar, estilete filiforme, estigma geralmente 2-lobado. Cápsula 2-valvada, loculicida, frequentemente com porção basal estéril sólida e porção seminal apical expandida, deiscência explosiva, retináculo (funículos modificados em projeções em forma de gancho), persistentes, raramente cápsula modificada rostrada (Thunbergia) ou carnosa (Avicennia); sementes 1-10, geralmente planas, orbiculares.

Tabela 1. Espécies de Acanthaceae da Marambaia, RJ, Brasil. CA: categoria de ameaça*, Vu: vulnerável, Mp: menor preocupação. AU: áreas urbanas, MA: manguezal, FA: floresta atlântica de encosta, AF: arbustiva fechada de pós-praia, FC: floresta de cordão arenoso. Ab: arbusto, Av: árvore, Er: erva, Sb: subarbusto, Tr: trepadeira).

Table 1. Acanthaceae species of Marambaia, Rio de Janeiro State, Brazil. CA: extinction risk category *, Vu: vulnerable, Mp: least concern. AU: urban areas, MA: mangrove, FA: Atlantic forest slope, AF: beach thicket, FC: sandy forest. Ab: shrub, Av: tree, Er: herb, Sb: subshrub, Tr: climber).

\begin{tabular}{lccccc}
\hline Espécies & $\mathrm{CA}$ & $\mathrm{AU}$ & $\mathrm{MA}$ & $\mathrm{FA}$ & \multicolumn{2}{c}{ Formações de Restinga } \\
\cline { 5 - 6 } & & $\mathrm{Mp}$ & & $\mathrm{Sb}$ & \\
Aphelandra longiflora & $\mathrm{Vu}$ & $\mathrm{Av}$ & & $\mathrm{FC}$ \\
$\begin{array}{l}\text { Avicennia schaueriana } \\
\text { Justicia brasiliana }\end{array}$ & $\mathrm{Vu}$ & & $\mathrm{Ab}$ & \\
$\begin{array}{l}\text { Justicia plumbaginifolia } \\
\text { Justicia cydoniifolia }\end{array}$ & $\mathrm{Mp}$ & & & $\mathrm{Sb}$ \\
$\begin{array}{l}\text { Ruellia blechum } \\
\text { Ruellia solitaria }\end{array}$ & $\mathrm{Vu}$ & $\mathrm{Er}$ & $\mathrm{Er}$ & \\
$\begin{array}{l}\text { Schaueria litoralis } \\
\text { Thunbergia alata }\end{array}$ & $\mathrm{Mp}$ & & & $\mathrm{Sb}$ \\
\hline
\end{tabular}


Chave para identificação das espécies americanas de Acanthaceae da Marambaia, RJ, Brasil

1. Árvores com raízes pneumatóforo; lâmina foliar com o ápice obtuso a emarginado ....... 1. Avicennia schaueriana

1. Ervas, arbustos ou subarbustos, raízes subterrâneas; lâmina foliar com o ápice agudo a acuminado

2. Flores com dois estames

3. Tirso terminal; corola branca; anteras com tecas coniventes

8. Schaueria litoralis

3. Cima axilar 1-3-flora, espiga axilar ou panícula terminal; corola vermelha, rósea ou branca e roxa; anteras com tecas divergentes, sobrepostas, subassimétricas, nunca coniventes

4. Arbusto ereto; inflorescência uma panícula de espigas terminal; brácteas vináceas a arroxeadas; corola rósea magenta 5. Justicia plumbaginifolia

4. Subarbusto com ramos escandentes; inflorescência axilar em cimas com 1-3 flores ou espigas congestas; brácteas verdes; corola arroxeada ou vermelha

5. Pecíolo 1,2-2,4 cm compr.; flores em cima escorpioide; brácteas oblongas a subespatuladas $3,5-4,2 \times 2-2,5 \mathrm{~mm}$; corola roxa e branca 4. J. cydoniifolia

5. Folhas subsésseis; flores em espigas secundifloras; brácteas lineares, as vezes oblanceoladas, 8-12 $\times 1-3 \mathrm{~mm}$; corola vermelha 3. J. brasiliana

2. Flores com quatro estames

6. Corola tubulosa, vermelha; anteras monotecas; 4 sementes 2. Aphelandra longiflora

6. Corola subinfundibuliforme, branca a lilás; anteras bitecas; sementes 5-14

7. Folhas $6,7-9,3 \mathrm{~cm}$ compr., ovadas; inflorescência um racemo terminal ereto 6. Ruellia blechum 7. Folhas 13,9-15,7 cm compr., lanceoladas a lanceolado-ovadas; flores 1-2 axilares 4. R. solitaria

\section{Aphelandra R.Br.}

Aphelandra em geral é caracterizado pela ausência de cistólitos, pela inflorescência terminal, simples ou composta, formadas por unidades de espigas, com flores decussadas densas, pela corola bilabiada ou tubulosa, com cinco lobos, e pelo androceu com quatro estames coniventes, às vezes com um estaminódio, e com as anteras monotecas rimosas, frequentemente apiculadas. É um gênero neotropical com ca. 230 espécies distribuídas desde o México até o sul do Brasil, ocorrendo através de áreas de florestas secas e úmidas até o Estado de Santa Catarina, no Brasil, e a província de Salta, na Argentina (Wasshausen 2013). No Brasil compreende 44 espécies (Profice et al. 2002) e na Marambaia é representado por Aphelandra longiflora.

\subsection{Aphelandra longiflora (Lindl.) Profice, Bradea} 10(1): 18. 2004.

Figuras 1b, 2, 5b-d

Subarbustos de até $1,5 \mathrm{~m}$ alt., estolonífero, ramos glabros. Folhas 13,5-21,6 × 3,2-4,4 cm, lanceoladas, ápice acuminado, base atenuada a decorrente no pecíolo, glabras na face superior, na inferior tricomas tectores nas nervuras, eglandulosas; pecíolo canaliculado, 1,2-2,9 $\mathrm{mm}$ compr., glabro. Panícula de espigas terminal, corimbiforme, até 4,8 cm compr., raque denso-pubescente; brácteas 5-7 $\times$ ca. $2 \mathrm{~mm}$, ápice agudo, denso-pilosas próximo à margem, tornando-se glabrescentes, esverdeadas, bractéolas como as brácteas, 2-3 $\times$ ca. $2 \mathrm{~mm}$. Flor séssil; cálice verde, 5 segmentos livres entre si, triangulares, 4-6,1 × 1-1,5 mm, ápice agudo, glabras, ciliados; corola tubulosa, 20-34,4 $\mathrm{mm}$ compr. total, tubo basal 1-3,1 mm compr., lobo anterior 3-4,2 mm compr., os demais 1-1,6 mm compr., lobo posterior suborbicular, ápice arredondado, os demais oblongos; estames 4 posteriores, subconiventes, subdidínamos, 20-24,2 mm compr., inseridos a 2,5-4,5 $\mathrm{mm}$ da base da corola, hirsutos no $1 / 3$ basal, anteras barbadas no ápice, com tufo de tricomas alvos, longos e densos, paralelas entre si, oblongas, 2,7-3 mm compr.; ovário 2,2-3 mm compr., glabro, 4 óvulos axiais, estilete ca. 23,0 mm, esparso-hirsuto, tricomas escassos na base, adensados no ápice, estigma subcrateriforme; frutos não encontrados.

Material examinado: BRASIL. Rio DE JANEIRO: Município Mangaratiba, Marambaia, Ilha da Marambaia, 14-V-2002 (fl), M. Conde 625 (RBR); 03VIII-2002 (fl), G.R. Siqueira 67 (RBR); 20-XII-2004 (bt), F.C. Nettesheim 55 (RBR); 18-X-2006 (fl.), D.M. Braz 80 (RBR).

Indivíduos de Aphelandra longiflora são facilmente reconhecidos pela inflorescência corimbiforme pouco ramificada, com espigas curtas, brácteas não ciliadas, pela corola tubulosa vermelha, pelas anteras barbadas no ápice, e pelos quatro lobos posicionados na parte posterior da corola, e o lobo 

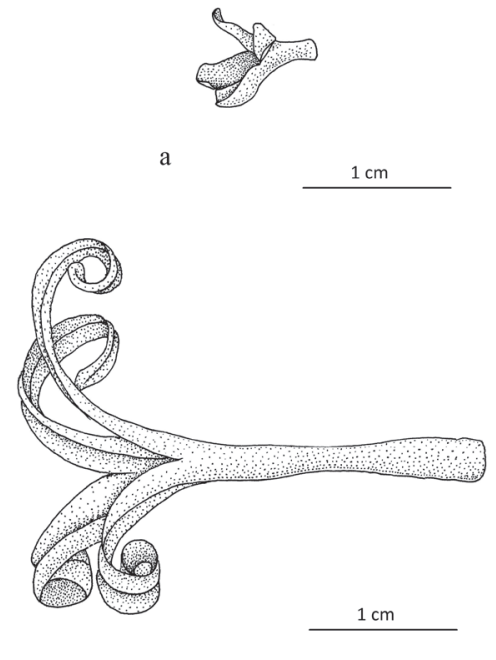

c

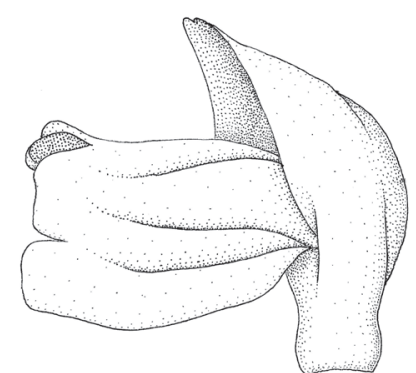

e

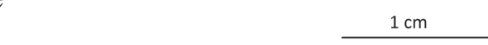

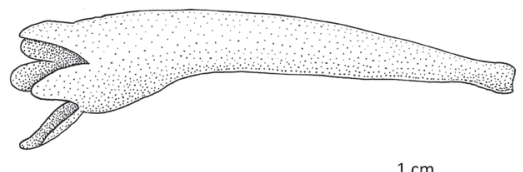
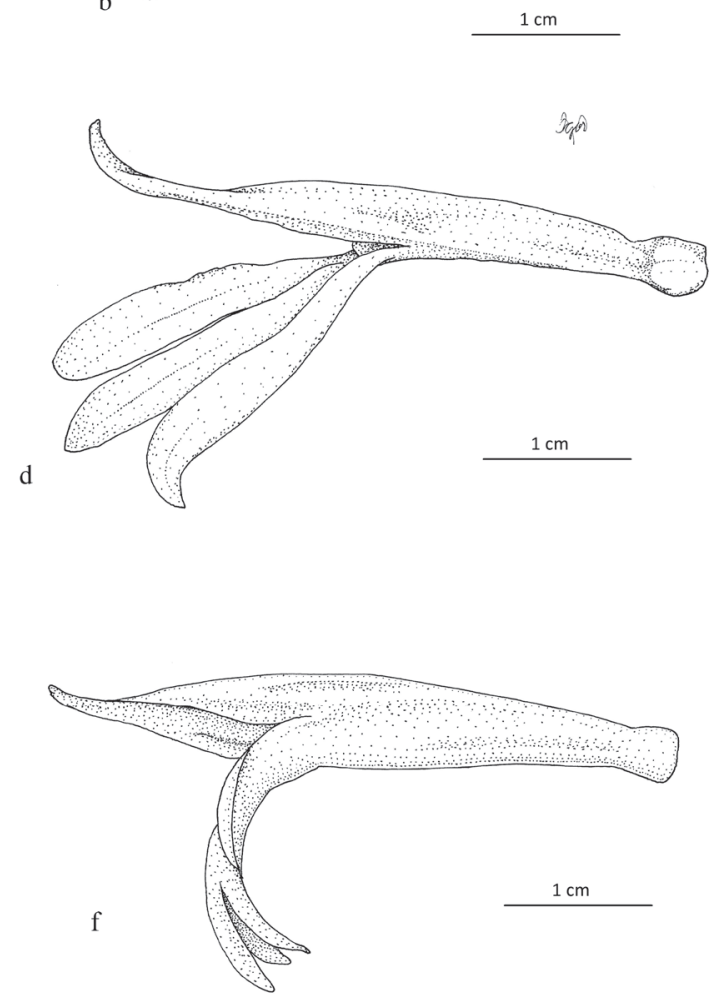
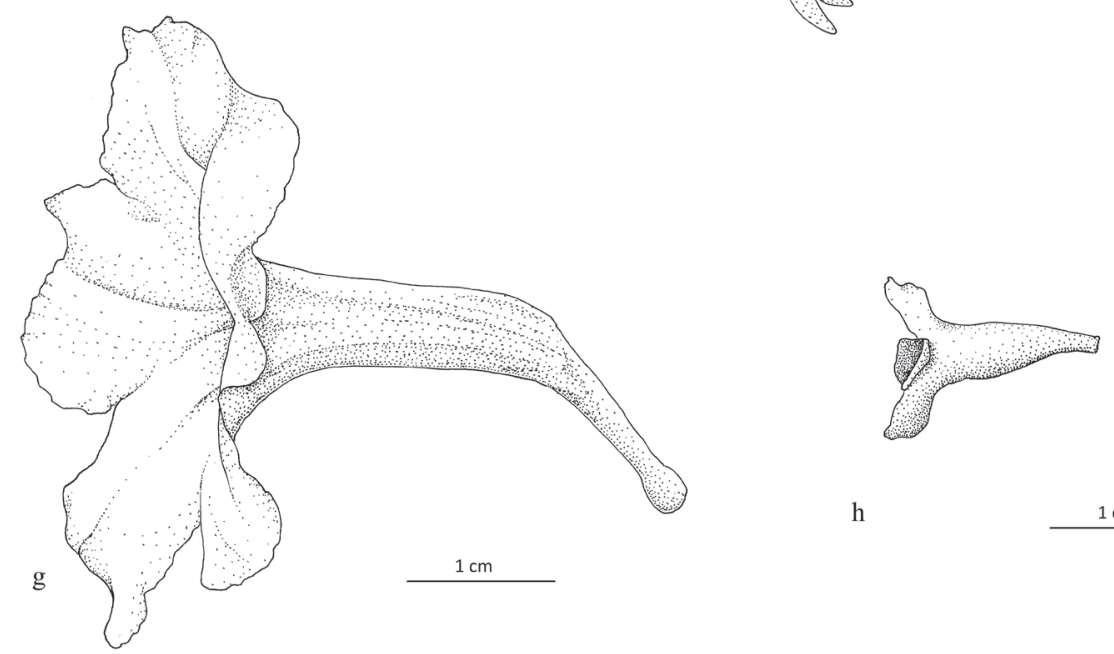

$\mathrm{h}$

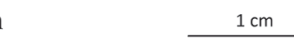

Figura 1. Acanthaceae da Marambaia, RJ, Brasil. Corolas em vista lateral. a. Avicennia schaueriana Stapf \& Leechm. ex Moldenke. b. Aphelandra longiflora (Lindl.) Profice. c. Schaueria litoralis (Vell.) A.L.A.Côrtes. d. Justicia plumbaginifolia Jacq. e. Justicia cydoniifolia (Nees) Lindau. f. Justicia brasiliana Roth. g. Ruellia solitaria Vell. h. Ruellia blechum L. (Ilustração: I.H.F. Azevedo).

Figure 1. Acanthaceae of Marambaia, Rio de Janeiro State,, Brazil. Corollas in lateral view. a. Avicennia schaueriana Stapf \& Leechm. ex Moldenke. b. Aphelandra longiflora (Lindl.) Profice. c. Schaueria litoralis (Vell.) A.L.A.Côrtes. d. Justicia plumbaginifolia Jacq. e. Justicia cydoniifolia (Nees) Lindau. f. Justicia brasiliana Roth. g. Ruellia solitaria Vell. h. Ruellia blechum L. (Illustration: I.H.F. Azevedo). 



Figura 2. Acanthaceae da Marambaia, RJ, Brasil. Aphelandra longiflora (Lindl.) Profice. a. Ramo florido. b. Inflorescência em detalhe. c. Corola em vista lateral. d. Corola aberta evidenciando o androceu. e. Antera em detalhe. f. Gineceu. g. Porção final do estilete e estigma. (Ilustração: I.H.F. Azevedo).

Figure 2. Acanthaceae of Marambaia, Rio de Janeiro State, Brazil. Aphelandra longiflora (Lindl.) Profice. a. Flowering branch. b. Inflorescence. c. Corolla in lateral view. d. Open corolla showing the androecium. e. Anther. f. Gynoecium. g. Tip of the style and stigma. (Illustration: I.H.F. Azevedo). 
anterior profundamente partido. As inflorescências e flores vistosas lhe conferem potencial ornamental a ser explorado. A. longiflora foi recente circunscrita com ampla variação morfológica e reunindo mais de 10 nomes sinonimizados, especialmente do gênero Geissomeria Lindl. (Profice \& Andreata 2011). Os indivíduos estudados diferem pelas inflorescências menores, pelas folhas sem tricomas glandulosos e pela ausência do estaminódio. A morfologia floral de A. longiflora é típica de plantas ornitófilas e outras espécies próximas (Geissomeria spp.) polinizadas por beija-flores já foram documentadas em áreas de florestas no sudeste do Brasil (Braz et al. 2000, Pereira 1998). Esses autores verificaram, por meio de testes in loco, que a reprodução se deu em altas taxas ou exclusivamente por meio de polinização cruzada nas duas outras espécies do gênero, indicando dependência da fauna nesse processo. Na área de estudo não foram observadas visitas dessas aves às flores de A. longiflora, o que pode explicar a dificuldade de sua frutificação. Por outro lado, seu hábito estolonífero permite uma estratégia a mais para sua reprodução. Na Marambaia, habita locais sombreados e úmidos no interior da floresta atlântica de encosta, próxima a rios e também ocorrendo sobre pedras, com seus indivíduos ocupando áreas mais ou menos extensas. Foi coletada com flores em maio, agosto, outubro e dezembro.

\section{Avicennia L.}

Avicennia é um dos gêneros típicos dos manguezais no Brasil e no mundo. Reúne cerca de oito espécies também representadas em regiões temperadas (Tomlinson 1986). Em geral, são plantas arbóreas com raízes especializadas (pneumatóforo), folhas especializadas para a excreção de sal e que se reproduzem por viviparidade, entre outras especializações para o ambiente. Relacionado às Verbenaceae e elevado à categoria de família em sistemas anteriores, Avicennia compartilha as sinapomorfias aceitas para as Acanthaceae, junto das Thunbergioideae (Borg et al. 2008, McDade et al. 2008, APG III 2009). No Brasil está representado por duas espécies e na Marambaia ocorre $A$. schaueriana.

\subsection{Avicennia schaueriana Stapf \& Leechm. ex}

Moldenke, Lilloa 4: 336. 1939.

Figuras 1a, 5e-h; Ilustração em Tomlinson (1986)

Árvores ou arvoretas, $2-7 \mathrm{~m}$ alt.; ramos glabros. Folhas 3,5-6,2 × 1,4-3,0 cm, elípticas a obovadas, ápice obtuso a emarginado, base aguda, glabras em ambas as faces, glândulas circulares em ambas as faces, densas nas folhas antigas; pecíolo comprimido, 3-10,0 mm compr., glabro. Dicásio paniculiforme terminal, até ca. 8,5 cm compr., raque denso-pubescente a incana; brácteas e bractéolas subtriangulares, 2,5-3,8 $\times 2,2-2,3 \mathrm{~mm}$, ápice agudo, base truncada, denso-pubescentes, esverdeadas. Flor séssil; cálice esverdeado, 5 segmentos quase livres entre si, oblongos a subtriangulares, 3-4,5 × 2-2,5 mm, ápice agudo, denso-pubescentes, não ciliados; corola subinfundibuliforme, branca a creme com mácula creme a amarela na fauce, $6,5-8,4 \mathrm{~mm}$ compr. total, tubo basal 2-2,8 mm compr., glabra, lobos densamente pilosos externamente, 3,5-4,7 mm compr., oblongos, o posterior com ápice arredondado a subemarginado; estames 4 alternos aos lobos da corola, 2 posteriores 2,2-2,5 mm compr., inseridos a 2-2,4 $\mathrm{mm}$ da base da corola, 2 anteriores 1,9-2,1 mm, inseridos a 1-1,5 $\mathrm{mm}$, glabros, anteras glabras, tecas paralelas entre si, oblongas, 0,8-0,9 mm compr.; ovário 2-3 mm compr., denso-hirsuto, 1-locular, 1-2 óvulos pêndulos, estilete 1-1,5 mm, glabro, estigma bífido, lobos subiguais, 0,5-0,7 mm compr.; fruto maduro verde, denso-piloso, unilocular, univalvo, semente única vivípara.

Material examinado: BRASIL. Rio DE JANEIRO: Município Mangaratiba, manguezal próximo ao exército, 17-XI-2006 (fl.), D.M. Braz 83 (RBR); Restinga da Marambaia (CAEX), Canal do Bacalhau, 1-X-2010 (fl.), C. Silva, N.M. Corrêa \& J.C.R. Moraes s.n. (RBE).

Avicennia schaueriana é amplamente dispersa desde as Antilhas e por toda a América do Sul na Costa Atlântica, desde as Guianas até o Uruguai (Tomlinson 1986). É uma das espécies arbóreas mais comuns nos manguezais brasileiros de norte a sul e, dentre as diversas características relacionadas ao ambiente do manguezal, suas folhas são comumente encontradas cobertas por cristais de sal. Suas flores são discretas, de cor branca a creme e, em geral, abrem poucas a cada vez na inflorescência. Na costa brasileira pode ser confundida com A. germinans (L.) L., que difere pelas folhas ovadas a lanceolado-ovadas e as flores maiores, com a corola densamente pilosa internamente e os estames longos, exsertos (Tomlinson 1986). $\mathrm{Na}$ Marambaia, indivíduos de A. schaueriana podem atingir porte mais elevado no interior do manguezal (até 7 alt.) ou podem ocorrer como arvoretas de pequeno porte (ca. $2 \mathrm{~m}$ alt.) nas áreas mais arenosas e no ecótono restinga-manguezal. Foi coletada com flores entre setembro e março e com frutos maduros entre dezembro e abril. 


\section{Justicia L.}

Justicia reúne cerca de 600 espécies distribuídas nos trópicos de todo o mundo (Graham 1990), sendo o gênero mais rico e complexo das Acanthaceae e altamente diversificado nas regiões tropicais e subtropicais da América do Sul (Ezcurra 2002). O monofiletismo do gênero, com a ampla circunscrição seguida na maioria dos estudos, não é suportado por bases moleculares (McDade et al. 2000, 2008), mas até que sejam feitos estudos mais detalhados esse conceito mais amplo vem se mantendo por diferentes autores. Para o Brasil são listadas 128 espécies de Justicia (Profice et al. 2015), com muitas destas contempladas nos extensos estudos taxonômicos de Ezcurra (2002), para a América do Sul austral, e de Wasshausen \& Wood (2003, 2004), para a Bolívia. Para o Brasil, merece destaque o estudo de Côrtes \& Rapini (2013) sobre a tribo Justicieae em parte do Estado da Bahia, onde foram registradas 27 espécies, sendo 17 de Justicia. Muitas espécies brasileiras permanecem tratadas apenas em sua descrição original. Representantes de Justicia L. podem ser reconhecidos pela presença de cistólitos nas folhas e ramos, pela corola bilabiada, com o lábio posterior geralmente 2-lobado e o anterior 3-lobado, pelo androceu com dois estames, anteras bitecas, sendo as tecas desiguais quanto a forma e/ou posição, e pelas cápsulas com quatro sementes e porção basal estéril sólida. Ocorrem na Marambaia Justicia brasiliana, J. cydoniifolia e J. plumbaginifolia.

3.1. Justicia brasiliana Roth, Nov. P1. Sp.: 17. 1821. Nome vulgar: "jacobina-vermelha"(Wasshausen \& Smith 1969)

Figura 1d; Ilustração em Wasshausen \& Smith (1969), Lorenzi \& Souza (2015)

Subarbusto 1-2 $\mathrm{m}$ alt., com ramos escandentes, glabros. Folhas 4-10(18) × 2-4 cm, lanceoladas a estreitamente-ovadas, ápice acuminado, base obtusa a cuneada, glabras a levemente pubérulas em ambas as faces, eglandulosas, subsesséis. Espiga axilar secundiflora, congesta, até $5 \mathrm{~cm}$ compr., raque glabra; brácteas lineares, as vezes oblanceoladas, 8-12 $\times 1-3 \mathrm{~mm}$, glabras a levemente pubescentes, uma fértil e a oposta estéril, bractéolas lineares a lanceoladas, ca. $5 \times 0,5 \mathrm{~mm}$, no mais como as brácteas. Flor séssil, cálice verde, 5 segmentos unidos entre si ca. $1 \mathrm{~mm}$, lanceolados, 3-4 mm compr., ápice agudo; corola bilabiada, vermelha, 30-45 mm compr. total, tubo basal ca. $25 \mathrm{~mm}$ compr., lábios 10-15 mm compr., posterior estreitamente ovado, ápice levemente bipartido, lábio anterior 3-lobado, lobos orbiculares, 3-5 mm compr.; estames levemente menores que o lábio posterior da corola, tecas levemente sobrepostas, ca. $2 \mathrm{~mm}$ compr., a inferior suboblíqua; ovário glabro; fruto não observado.

Material examinado: BRASIL. RIo DE JANeIRo: Município do Rio de Janeiro, Restinga da Marambaia; 21-XI-1997 (fl), D.S.D. Araújo 10601 (GUA).

Justicia brasiliana ocorre na Argentina, Paraguai, Uruguai e, no Brasil é encontrada principalmente às margens de estradas, trilhas e cursos d'água, em áreas florestadas por toda a região sul (Ezcurra 2002), se estendendo a norte até o Mato Grosso do Sul, São Paulo, Minas Gerais e Rio de Janeiro (Profice et al. 2015). Caracteriza-se pelas flores agrupadas em inflorescências axilares, secundifloras, congestas, e pela corola bilabiada, vermelha e vistosa. Por essas características é cultivada como ornamental (Lorenzi \& Souza 2008). É encontrada no interior da floresta atlântica, nas margens de matas e capoeiras, e no Rio de Janeiro é uma espécie comum nas restingas (em Armação de Búzios, Cabo Frio, Saquarema, Maricá, Araruama e Rio de Janeiro). Na Maramabaia, ocorre sobre dunas, na Formação Arbustiva Aberta de Pós-praia. Embora não observada com frutos na Marambaia, em outras localidades foi coletada com flores e frutos praticamente o ano todo, mas principalmente entre fevereiro e maio e setembro e novembro.

3.2. Justicia cydoniifolia (Nees) Lindau, in Nat. Pflanzenfam. (Engler \& Prantl) 4; Abt. 3b: 350. 1895.

Figuras 1e, 6a-b; Ilustração em Nees (1847).

Subarbustos com ramos escandentes, tomentosos. Folhas 7,6-9,4 × 2,9-4,2 cm, ovadas a elípticas, ápice agudo, base obtusa a aguda, pilosa em ambas as faces, tomentosas nas nervuras e próximo à margem, eglandulosas; pecíolo cilíndrico a rasocanaliculado, 12-23,8 mm compr., denso-hirsuto. Cima axilar laxa, escorpióide, 1-5 flores; brácteas ovado-oblongas, 3,5-4 × 2-2,5 mm, ápice arredondado a obtuso, base truncada, geralmente denso-hirsutas, castanho-esverdeadas, bractéolas como as brácteas, 5-7,2 × 2,3-2,7 mm. Pedicelo 3-4 mm compr.; cálice esverdeado, 5 segmentos livres entre si, elípticos, 7-8,1 × 1,9-2,2 mm, ápice agudo, tricomas alvos, curtos, esparsos, tricomas glandulosos raros, não ciliados; corola bilabiada, lábio inferior roxo, superior 
esbranquiçado, 25-30 mm compr. total, tubo basal ca. $5 \mathrm{~mm}$ compr., lábios 14-17,1 mm compr., posterior subtriangular, ápice levemente bipartido, lábio anterior 3-lobado, lobos orbiculares, 6,5-7,3 mm; estames 18-22 mm compr., inseridos a 6-7,2 $\mathrm{mm}$ da base da corola, glabros, anteras glabras, tecas sobrepostas, ca. $3 \mathrm{~mm}$ compr.; ovário ca. 3,5 mm compr., glabro, estilete ca. $23 \mathrm{~mm}$, glabro, estigma bífido, lobos subiguais, 1,3-1,8 mm compr.; fruto $14-19 \times$ ca. $10,2 \mathrm{~mm}$, porção basal estéril ca. $8 \mathrm{~mm}$ compr., porção seminal globosa, esverdeado.

Material examinado: BRASIL. Rio DE JANEIRo: Município Mangaratiba, Marambaia, Ilha da Marambaia, 14-X-2002 (fl), L.F.T. Menezes 535 (GUA).

Material adicional examinado: Espírito Santo, Presidente Kennedy, Restinga de Praia das Neves, 8-VIII-2008 (fl), D.M. Braz 219 (RBR).

Justicia cydoniifolia foi descrita para diversas localidades do Rio de Janeiro (Nees 1847) mas sua distribuição também foi verificada no Espírito Santo, em Minas Gerais e no Paraná, na floresta ombrófila (Profice et al. 2015) e também em áreas da floresta estacional. Essa espécie é reconhecida por seu hábito com ramos escandentes, as flores vistosas, uma a poucas nas axilas foliares, as bractéolas maiores que as brácteas, todas ovado-oblongas. Em função dos longos ramos escandentes é comumente citada como planta trepadeira. J. cydoniifolia é uma espécie comum nas florestas e restingas fluminenses, registrada nas matas de restinga e na restinga arbustiva em Maricá, Saquarema (Jacarepiá) e Rio de Janeiro (Grumari). $\mathrm{Na}$ Marambaia foi encontrada na Floresta de Cordão Arenoso. Foi coletada com flores em outubro, mas floresce e frutifica principalmente entre os meses de junho a agosto.

3.3. Justicia plumbaginifolia J.Jacq., Ecl. P1. Rar. 1(2): 20, t. 2. 1811.

Figuras 1f, 3, 6c-f

Arbustos, 0,9-1,5 m alt.; ramos glabros. Folhas 14,5-23 × 3,2-6,1 cm, elípticas, ápice agudo a acuminado, base aguda a decorrente no pecíolo, glabras em ambas as faces, eglandulosas; pecíolo canaliculado, 8-30,1 mm compr., glabro. Panícula de espigas terminal, congesta, $5-8,5 \mathrm{~cm}$ compr., raque glabra; brácteas ovado-lanceoladas, 35-46 × 4,9-7,1 mm, ápice agudo, base longo-aguda, glabras, verdes na base, vináceas no ápice, bractéolas como as brácteas, 33-38 × 2,2-3,1 mm. Flor subséssil; cálice vináceo, 5 segmentos unidos entre si 1-2 mm, lanceolados, 19-22,3 × 3-4,1 mm, ápice agudo a levemente acuminado, tricomas eretos, curtos, esparsos, não ciliados; corola bilabiada, rósea magenta, esbranquiçada na base, $42-47 \mathrm{~mm}$ compr. total, tubo basal ca. $4 \mathrm{~mm}$ compr., lábios 12-23 mm compr., posterior oblongo, ápice levemente bipartido, lábio anterior 3-lobado, lobos oblongos, laterais 18-21 mm compr., o central $19-20 \mathrm{~mm}$; estames $22-25 \mathrm{~mm}$ compr., inseridos a $14-17 \mathrm{~mm}$ da base da corola, glabros, anteras glabras, tecas oblíquas pela expansão do conectivo, levemente sobrepostas, 3,2-4,5 mm compr.; ovário ca. 4,2 mm compr., glabro, estilete 41-46 mm, glabro, estigma com lobos subiguais, 0,5-0,7 mm compr.; fruto $12-13,2 \times$ ca. $4,5 \mathrm{~mm}$, porção basal estéril ca. $2,5 \mathrm{~mm}$ compr., comprimida, porção seminal globosa sulcada, castanho escuro no ápice, claro na base.

Material examinado. BRASIL: Rio DE JANEIRo: Município Mangaratiba, Marambaia, Ilha da Marambaia, 14-V-2002 (fl), G.V. Somner et al. 1009 (RBR); 18-II-2006 (fl), F.C. Nettesheim 179 (RBR); 10-VI-2008 (fr), V.C. Cysneiros 01 (RBR).

Justicia plumbaginifolia ocorre nos Estados do Rio de Janeiro, São Paulo e Espírito Santo, na floresta ombrófila (Profice et al. 2015). É reconhecida pelas inflorescências vistosas, com brácteas, bractéolas e cálice vináceos e a corola rósea patente e, em função de sua beleza, é uma espécie nativa com grande potencial ornamental. É uma espécie comum nas florestas fluminenses e na Marambaia ocorre no interior da floresta atlântica de encosta. Floresce e frutifica principalmente entre fevereiro e maio.

\section{Ruellia L.}

Ruellia reúne aproximadamente 260 espécies (Tripp 2007), com ampla distribuição nos trópicos e subtrópicos de todo o mundo, sendo o novo mundo seu mais importante centro de diversidade (Ezcurra 1993). É um gênero monofilético, embora não fortemente sustentado com bases moleculares (Tripp 2007). Diversas espécies brasileiras foram tratadas em ampla revisão do gênero para a América do Sul austral (Ezcurra 2002) e para a Bolívia (Wasshausen \& Wood 2003, 2004). Para o Brasil são listadas 84 espécies (Profice et al. 2015) e, juntamente com Justicia, é um dos gêneros mais ricos em levantamentos regionais da família. Ruellia reúne 22 espécies no Estado de Minas Gerais (Pessôa 2012), 12 no Paraná (Silva 2011) e nove no Rio de Janeiro (Baumgratz et al. 2014). De forma 


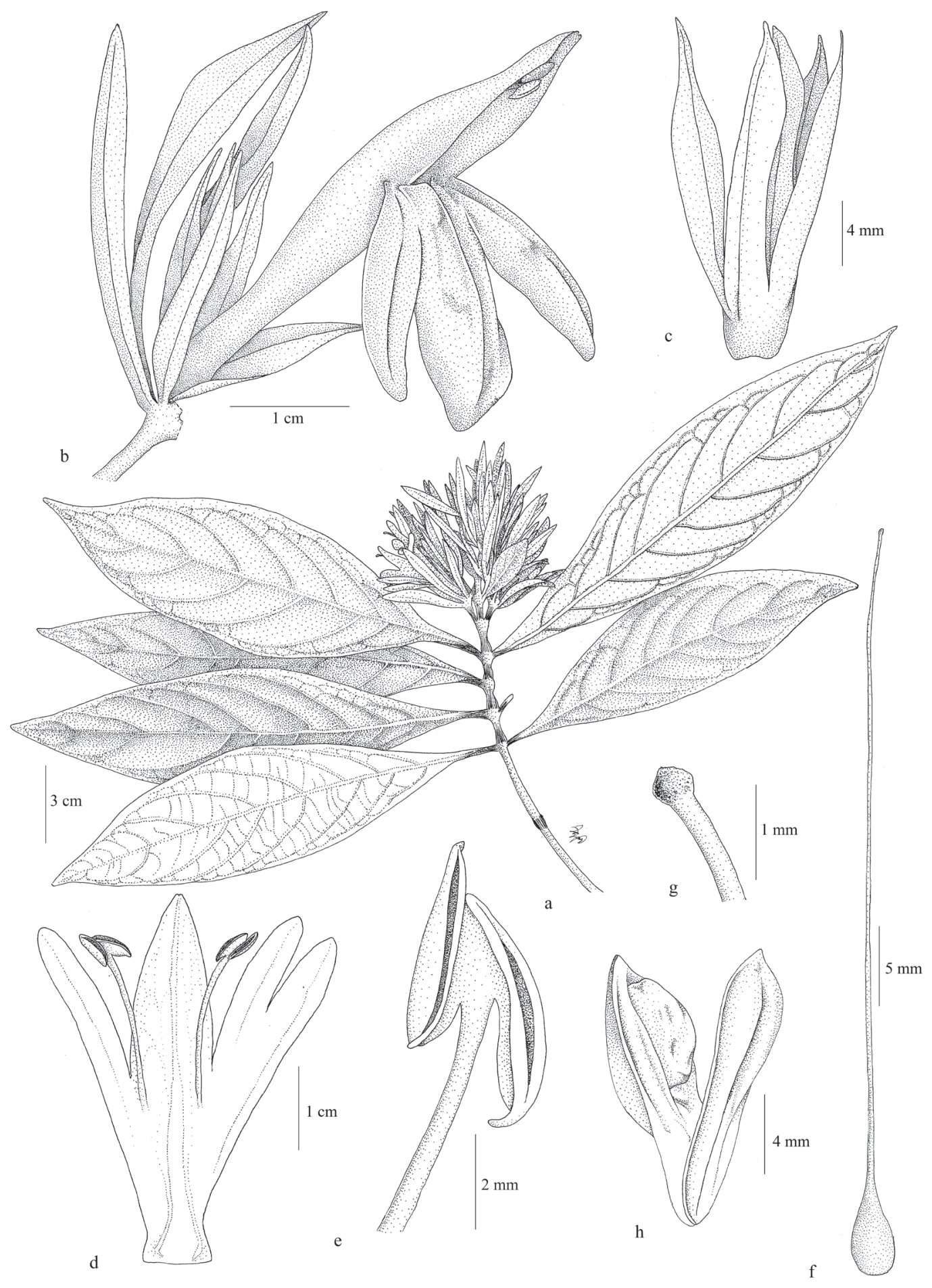

Figura 3. Acanthaceae da Marambaia, RJ, Brasil. Justicia plumbaginifolia Jacq. a. Ramo florido. b. Flor acompanhada de brácteas e bractéolas. c. Cálice. d. Corola aberta evidenciando o androceu. e. Antera em detalhe. f. Gineceu. g. Estigma em vista frontal com os lobos fechados. h. Fruto aberto com semente. (Ilustração: I.H.F. Azevedo).

Figure 3. Acanthaceae of Marambaia, Rio de Janeiro State, Brazil. Justicia plumbaginifolia Jacq. a. Flowering branch. b. Flower wih bracts and bracteoles. c. Calyx. d. Open corolla showing the androecium. e. Anther. f. Gynoecium. g. Stigma in frontal view with closed lobes. h. Open fruit with seed. (Illustration: I.H.F. Azevedo). 
geral, seus representantes são herbáceos ou arbustivos, apresentam cistólitos, flores leve a fortemente zigomorfas, corola comumente subinfundibuliforme, androceu com quatro estames didínamos, unidos dois a dois por membrana estaminal, e as anteras bitecas, com tecas paralelas e múticas. Na Marambaia está representado por Ruellia blechum L. e R. solitaria Vell.

4.1. Ruellia blechum L., Syst. Nat. ed. 10, 2: 1120. 1759.

Figuras 1h, 7a-c; Ilustração em Wasshausen (1995)

Erva estolonífera e com ramos eretos até $0,5 \mathrm{~m}$ alt., glabros. Folhas 6,7-9,3 × 3,1-4,4 cm, ovadas, ápice agudo a curtamente acuminado, base obtusa, tricomas alvos, raros em ambas as faces, adensados nas nervuras da face superior, eglandulosas; pecíolo levemente comprimido, 2,2-2,9 mm compr., glabrescente. Espiga terminal alongada, 3-15 cm compr., raque glabrescente; brácteas ovadas, 12-16,1 × 10,9-12,2 mm, ápice agudo, base obtusa, verdes, ciliadas, com tricomas alvos patentes, subdensos, bractéolas lanceoladoovadas, $8,1-10,1 \times$ ca. $3,2 \mathrm{~mm}$, de resto como as brácteas. Flor séssil a pedicelo até $2,3 \mathrm{~mm}$ compr.; sépalas 5 , hialinas, unidas ca. $1 \mathrm{~mm}$ compr., subuladas, 3,2-3,8 $\times$ ca. $0,3 \mathrm{~mm}$, ápice agudo, esparso-hirsutas, irregularmente ciliadas; corola subinfundibuliforme, branca a lilás claro, 11-14,2 mm compr. total, tubo basal 5,1-7,2 mm compr., lobos ca. 2,5 mm compr., orbiculares, ápice arredondado; estames inseridos a $6,5-8,3 \mathrm{~mm}$ compr. da base da corola, 2 posteriores 1,8-3 mm compr., 2 subposteriores 1,3-2,5 mm compr., glabros, anteras glabras, sagitadas, ca. 1-1,3 mm compr.; ovário ca. 1,7 mm compr., esparso-hirsuto na base, adensado no ápice, 2-locular, 9-15 óvulos axilares, estilete ca. 7,2 mm compr., denso-piloso em direção ao ápice, estigma bífido, lobos desiguais, um vestigial, o outro 1,1-1,4 mm compr.; fruto 6-7,5 × 3,9-5 mm, subgloboso, septo rompendo-se na base da valva, paleáceo.

Material examinado: BRASIL. Rio DE JANEIRo: Município Mangaratiba, Marambaia, Ilha da Marambaia, 19-X-2006 (fl), D.M. Braz et al. 82 (RBR).

Ruellia blechum é uma planta amplamente dispersa em toda a América do Sul e Central em áreas úmidas ou secas de vegetação aberta, degradada ou próxima a áreas cultivadas (Wasshausen 1995). Foi descrita para a Jamaica e é considerada naturalizada no Brasil, onde está distribuida em parte do Nordeste, do Centro-oeste e do Sudeste (Profice et al. 2016). $\mathrm{Na}$ Marambaia foi encontrada nos arredores de construções abandonadas, nas proximidades da floresta de encosta. É uma erva pequena que forma tapetes densos, com espigas terminais com brácteas, bractéolas e cálice verdes e corola branca. Floresce e frutifica praticamente o ano todo, mas principalmente nos meses de setembro e outubro.

\subsection{Ruellia solitaria Vell., Fl. Flum. 266. 1829.}

Figura 1g, 7d-e

Erva ereta a subarbustiva, até $1,5 \mathrm{~m}$ alt.; ramos denso-pilosos nas extremidades, glabrescentes na base, tricomas curtos, alvos, eretos. Folhas 13,9-15,7 × 3-3,4 cm, lanceoladas a lanceoladoovadas, ápice acuminado a longo-acuminado, base aguda, face superior glabra, inferior pilosa apenas na nervura central, raramente nas secundárias, eglandulosas; pecíolo canaliculado, 1-1,3 mm compr., piloso a glabrescente. Cima de 1-2 flores nas axilas das folhas apicais, cada flor com um par de bractéolas elípticas, 12-17,1 × 4,5-6 mm, ápice longo-acuminado, base aguda, glandulosas e pilosas nas nervuras, não ciliadas, verdes. Flor séssil; cálice branco-esverdeado, 5 segmentos unidos ca. $1,3 \mathrm{~mm}$, triangulares a subulados, 5-10,1 × 6-7 mm, ápice agudo a longo-agudo, pilosos, não ciliados; corola subinfundibuliforme, branca, 49-62 mm compr. total, tubo basal 10-15 mm compr., lobos ca. 1,3-1,8 mm compr., suborbiculares, ápice arredondado; estames 4 didínamos, inseridos a 9,8-15,2 mm compr. da base da corola, 2 posteriores 13-14,2 mm compr., 2 subposteriores 9-10,1 mm compr., glabros, anteras glabras, oblongas, 3-3,5 mm compr.; ovário ca. 3,3 mm compr., glabro, 5-9 óvulos axilares, estilete 2,3-2,6 mm compr., denso-hirsuto na base, esparso em direção ao ápice, estigma bífido, lobos desiguais, um vestigial, o outro 1,3-1,5 mm compr.; fruto não observado.

Material examinado: BRASIL. Rio DE JANEIRO: Município Mangaratiba, Marambaia, Ilha da Marambaia, 16-VII-2003 (fl), L.F.T. Menezes et al. 1094 (RBR).

Material adicional examinado: Espírito Santo, Presidente Kennedy, Restinga de Praia das Neves, 9-VIII-2008, M.M.T. Rosa 532.

Ruellia solitaria distribui-se por todos os Estados do sudeste do Brasil, até o Paraná (Profice et al. 2015), sendo relativamente frequente na Serra do 


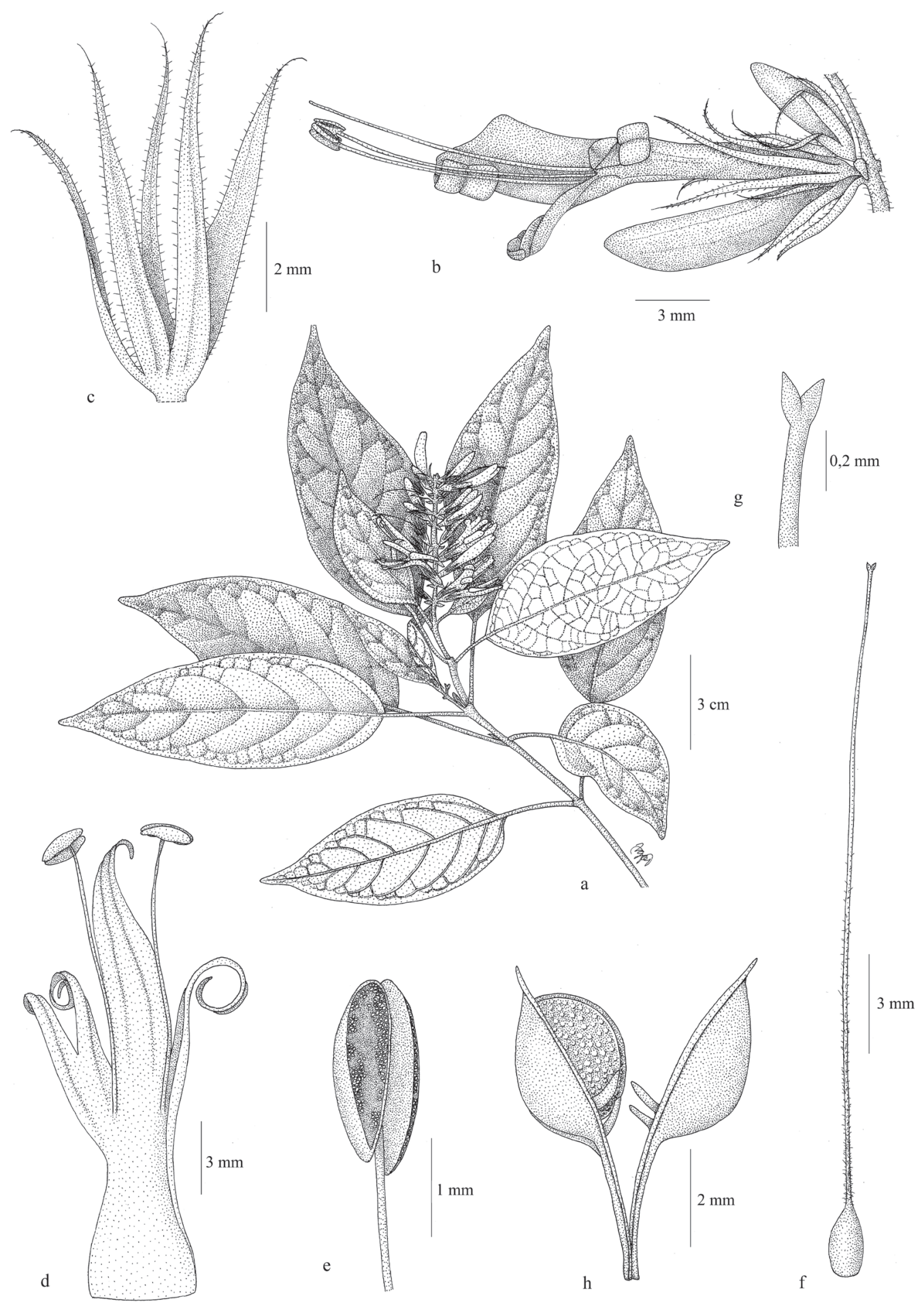

Figura 4. Acanthaceae da Marambaia, RJ, Brasil. Schaueria litoralis (Vell.) A.L.A.Côrtes. a. Ramo florido. b. Cima com flor aberta e botões florais. c. Cálice. d. Corola aberta evidenciando o androceu. e. Antera em detalhe. f. Gineceu. g. Estigma em detalhe. h. Fruto aberto com sementes. (Ilustração: I.H.F. Azevedo).

Figure 4. Acanthaceae of Marambaia, Rio de Janeiro State, Brazil. Schaueria litoralis (Vell.) A.L.A.Côrtes. a. Flowering branch. b. Cyme with open flower and buds. c. Calyx. d. Open corolla showing the androecium. e. Anther. f. Gynoecium. g. Stigma. h. Open fruit with seeds. (Illustration: I.H.F. Azevedo). 

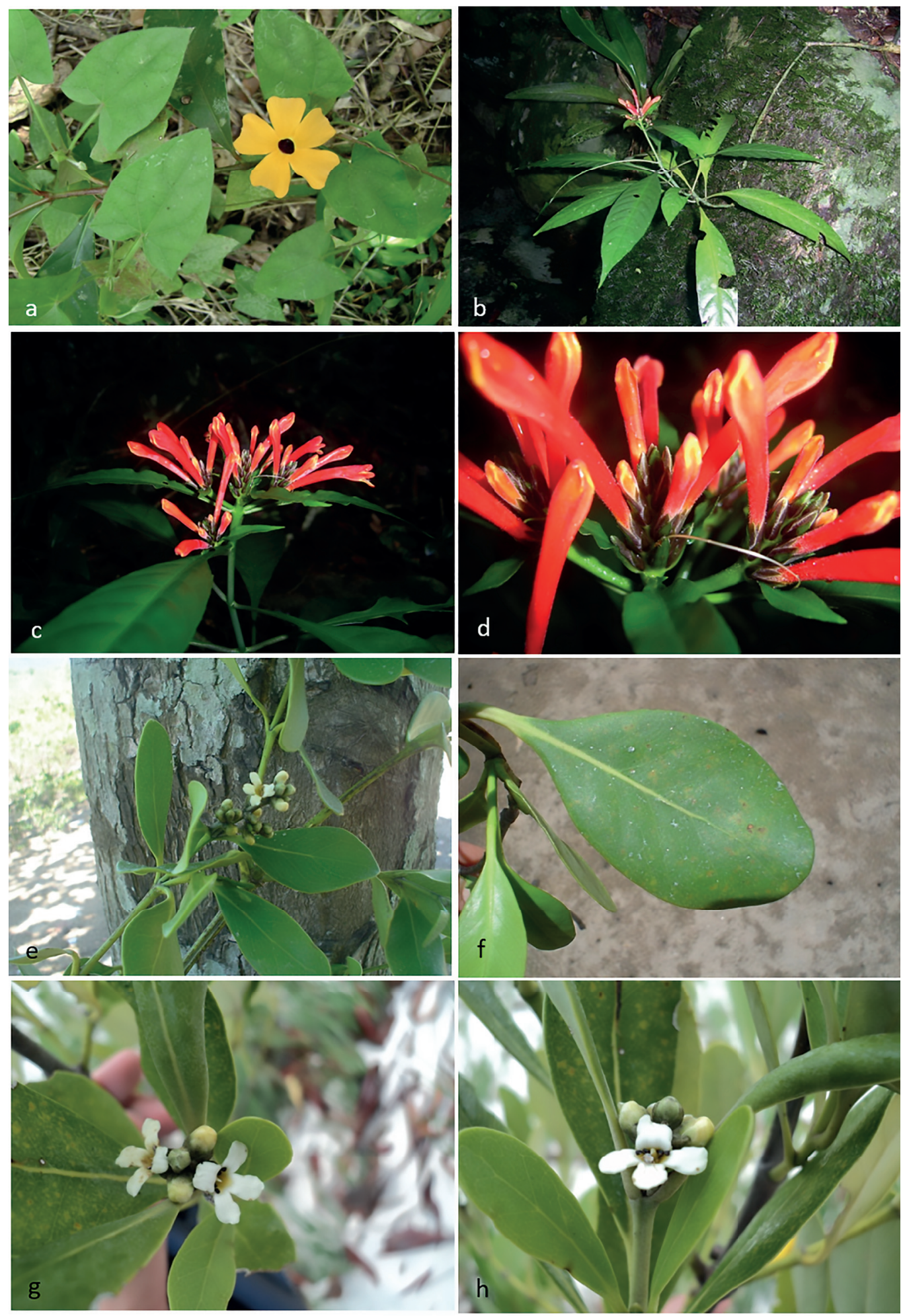

Figura 5. Acanthaceae da Marambaia, RJ, Brasil. Thunbergia alata Poir. a. Ramo florido. Aphelandra longiflora (Lindl.) Profice. b. Planta no interior da floresta. c. Ramo florido. d. Inflorescência com botões em detalhe. Avicennia schaueriana Stapf \& Leechm. ex Moldenke. e. Tronco e ramo florido. f. Folha com cristais de sal excretado sobre a superfície. g. Vista superior da inflorescência. h. Flor em vista frontal. (Fotos: a, e-f- D.M. Braz; b-d- A.V.S. Couto; g-h- C. da Silva).

Figure 5. Acanthaceae of Marambaia, Rio de Janeiro State, Brazil. Thunbergia alata Poirier. a. Flowering branch. Aphelandra longiflora (Lindl.) Profit. b. Plant inside the forest. c. Flowering branch. d. Inflorescence with buds. Avicennia schaueriana Stapf \& Leechm. ex Moldenke. e. Trunk and flowering branch. f. Leaf with salt crystals. g. Top view of the inflorescence. h. Flower in frontal view. (Photos: the e-f-D.M. Braz b-d-A.V.S. Couto g-h-C. da Silva). 

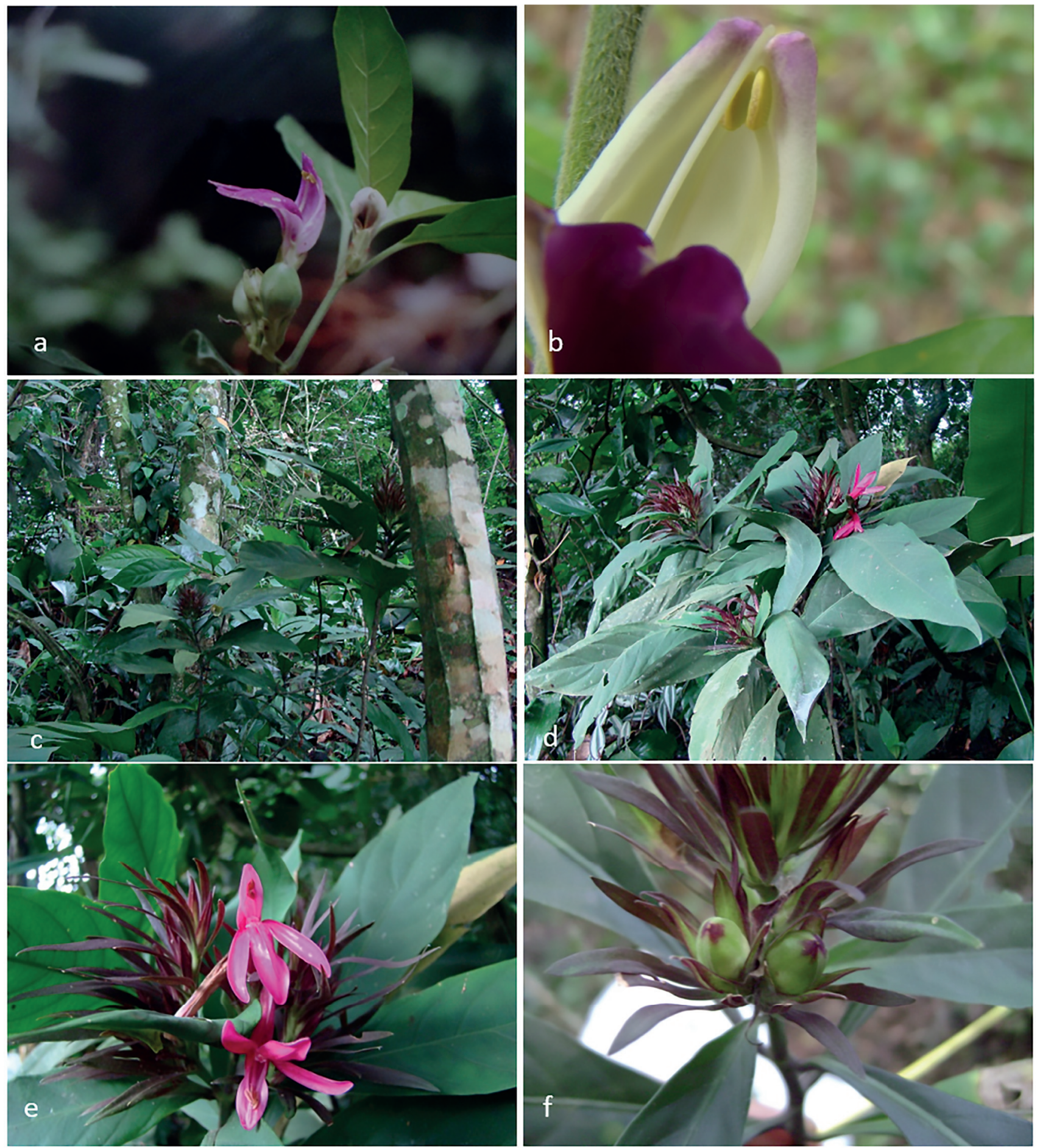

Figura 6. Acanthaceae da Marambaia, RJ, Brasil. Justicia cydoniifolia (Nees) Lindau. a. Ramo com flor e frutos imaturos. b. Detalhe da flor, evidenciando parte do gineceu e do androceu. Justicia plumbaginifolia Jacq. c. Indivíduos no interior da floresta. d. Ramos floridos. e. Inflorescência em detalhe, evidenciando a corola. f. Inflorescência passada com frutos imaturos (Fotos: a, c-f- D.M. Braz; b- A.V.S. Couto).

Figure 6. Acanthaceae of Marambaia, Rio de Janeiro State, Brazil. Justicia cydoniifolia (Nees) Lindau. a. Branch with flower and immature fruits. b. Detail of flower showing part of gynoecium and androecium. Justicia plumbaginifolia Jacq. c. Plant inside the forest. d. Flowering branches. e. Detail of inflorescence showing the corolla. f. Old inflorescence with immature fruits (Photos: a, c-f- D.M. Braz; b- A.V.S. Couto). 

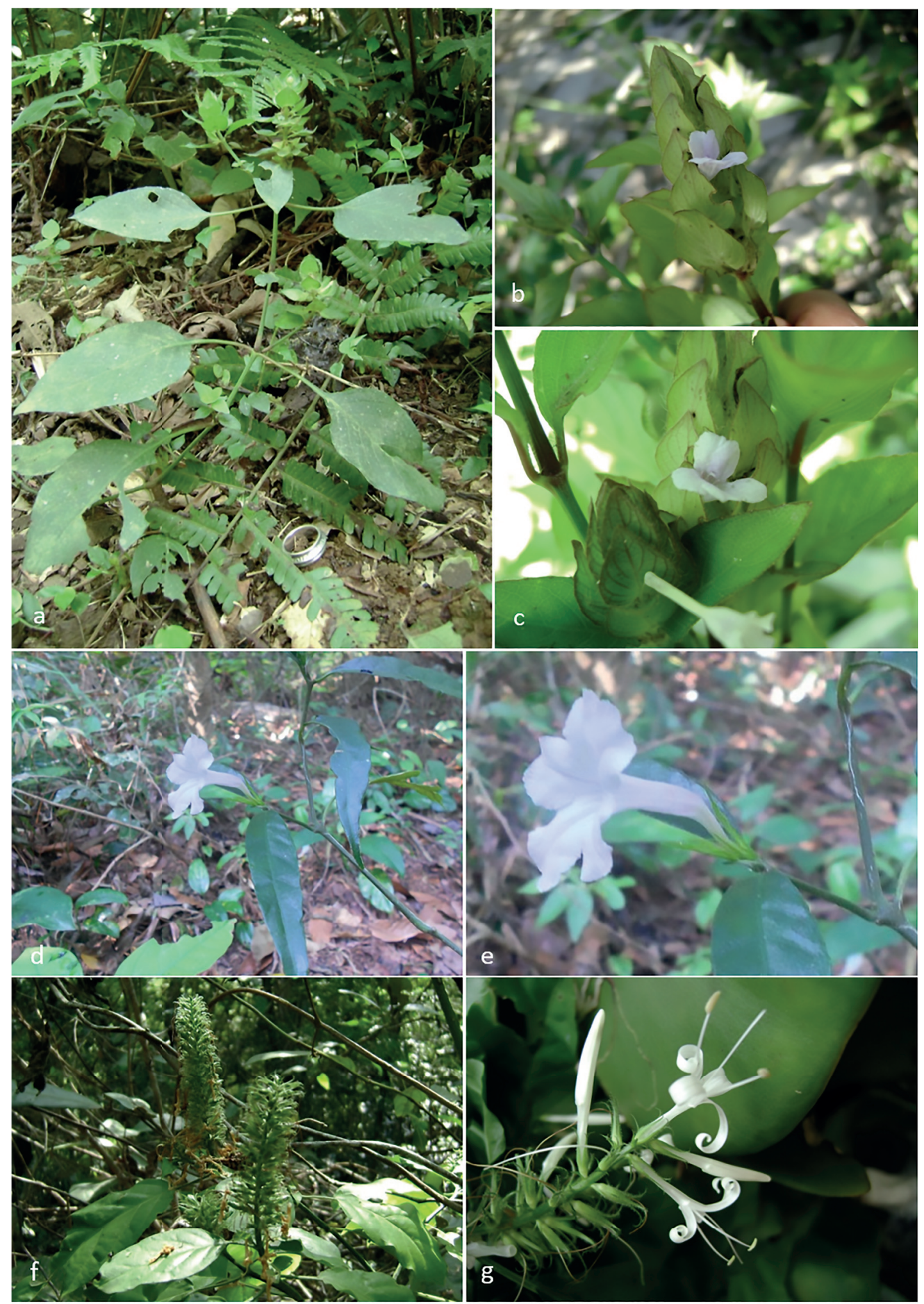

Figura 7. Acanthaceae da Marambaia, RJ, Brasil. Ruellia blechum L. a. Indivíduo às margens da floresta. b. Inflorescência. c. Flores com corola aberta em vista frontal. Ruellia solitaria Vell. d. Indivíduo no interior da floresta. e. Flor em vista lateral. Schaueria litoralis (Vell.) A.L.A.Côrtes. f. Inflorescência passada com frutos jovens. g. Inflorescência com flor aberta. (Fotos: a-c, f-g- D.M. Braz; d-e- I.H.F. Azevedo).

Figure 7. Acanthaceae of Marambaia, Rio de Janeiro State, Brazil. Ruellia blechum L. a. Plant at forest edge. b. Inflorescence. c. Flowers with open corolla in frontal view. Ruellia solitaria Vell. d. Plant inside the forest. e. Flower in lateral view. Schaueria litoralis (Vell.) A.L.A.Côrtes. f. Old inflorescence with young fruits. g. Inflorescence with open flower. (Photos: a-c, f-g- D.M. Braz d-e I.H.F. Azevedo). 
Mar e em regiões litorâneas e tornando-se rara em direção ao interior (Kameyama 1995). Kameyama (1995) registrou essa espécie em um afloramento de calcário na base da Serra do Cipó, nas proximidades do Cerrado. É uma erva delicada, com flores isoladas nas axilas foliares, com corola vistosa branca a levemente lilás e ca. de $5 \mathrm{~cm}$ comprimento, sendo cada flor acompanhada por um par de bractéolas bem desenvolvidas que cobrem ao menos o terço basal da corola Ruellia solitaria floresce e frutifica entre maio e setembro, contudo, na área de estudo seus frutos não foram observados.

\section{Schaueria Nees}

Schaueria é um gênero monofilético endêmico da Floresta Atlântica brasileira, que reúne 13 espécies distribuídas da Bahia ao Rio Grande do Sul (Côrtes et al. 2016). São plantas arbustivas a subarbustivas, caracterizadas pelas bráctea, bractéolas e segmentos do cálice filiformes, a corola branca a amarela bilabiada, com lábio superior comumente inteiro a bilobado, ereto ou inflexo, e o lábio inferior trilobado, os estames exsertos e as anteras bitecas com tecas paralelas, iguais, múticas, e estaminódios ausentes (Cortês \& Rapini 2013). Compartilha o androceu com dois estames e a cápsula clavada, estipitada, 4-seminada, com outros gêneros de Justicieae. Na Marambaia está representado por Schaueria litoralis.

\subsection{Schaueria litoralis (Vell.) A.L.A.Côrtes, P1. Syst.}

Evol. 302: 833. 2016.

Figuras 1c, 4, 7f-g

Arbustos, ca. 1,0 m alt.; ramos glabros. Folhas 7,9-10,2 × 2,2-4,3 cm, elípticas a ovado-elípticas, ápice acuminado, base obtusa a aguda, glabras em ambas as faces, eglandulosas; pecíolo canaliculado a comprimido, 21-42 mm compr., glabro. Tirso terminal com fascículos de 1-3 flores em cada bráctea, $7-11,4 \mathrm{~cm}$ compr., raque pilosa, glabrescente em direção ao ápice; brácteas subuladas, 5-6,5 × 2-2,7 mm, ápice agudo, base truncada, ciliadas, glabras, verdes, ciliadas, bractéolas subuladas, 2-3,2 × 1,3-2,1 mm. Pedicelo floral 2-2,9 mm compr.; cálice verde, 5 segmentos unidos entre si 1-2,1 mm, subulados, 9-14,3 $\times$ ca. 1 $\mathrm{mm}$, ápice longo-agudo, ciliados, tricomas glandulosos esparsos a hirsutos; corola bilabiada, branca, $18-23 \mathrm{~mm}$ compr. total, tubo basal 8-11 mm compr., lábio anterior 3-lobado, lobos linear-oblongos, 11-14,1 mm compr., lábio posterior linear-oblongo, 10-14,2 $\mathrm{mm}$ compr., ápice inteiro; estames 11,5-15,1 mm compr., inseridos a 5-8,5 mm compr. da base da corola, glabros, anteras glabras, sagitadas, 2-2,5 mm compr.; ovário ca. 3,1 mm compr., glabro, estilete ca. $20 \mathrm{~mm}$ compr., esparsohirsuto, estigma bífido, lobos subiguais, 0,2-0,3 mm compr.; fruto 6-11 × 2,8-4 mm, porção basal estéril ca. $1 / 2$ compr., porção seminal esferoidal, castanho.

Material examinado: BRASIL. Rio DE JANEIRo: Município Mangaratiba, restinga de Marambaia, área de pós-praia, praia da Gaeta próximo à Ilha de Marambaia, 17-IX-2003 (fl), L.F.T. Menezes et al. $1064 a$ (RBR); Praia da Gaeta, 23-XII-2004 (fl), L.F.T. Menezes et al. 1305 (RBR).

Material adicional examinado: BRASIL. Espírito Santo, Presidente Kennedy, Restinga de Praia das Neves, 18-X-2008 (fl), D.M. Braz 225 (RBR).

Schaueria litoralis ocorre no Rio de Janeiro, Espírito Santo, Minas Gerais e São Paulo e, na Bahia, é conhecida apenas pelo material tipo (Côrtes et al. 2016). É uma planta subarbustiva com inflorescência terminal de brácteas, bractéolas e cálice subulados, verdes, e corola branca com cerca de $2 \mathrm{~cm}$ de comprimento. $S$. litoralis é encontrada nas restingas fluminenses (Cabo Frio, Rio de Janeiro) e na Marambaia foi coletada na floresta de cordão arenoso. Floresce principalmente entre julho e outubro e frutifica entre agosto e novembro.

\section{Agradecimentos}

Agradecemos a Fundação Carlos Chagas Filho de Amparo à Pesquisa do Estado do Rio de Janeiro - FAPERJ, pelo apoio financeiro ao estudo; aos colegas e estagiários do Departamento de Botânica da UFRRJ, Alexandre Medeiros, Arthur Couto, Christian da Silva, Deborah Hottz, Vinicius Cysneiros, Vanessa Santana e Guilherme Rodrigues que auxiliaram nos trabalhos de campo; ao CADIM-Marambaia, à Marinha do Brasil e responsáveis encarregados das visitas, pelo apoio logístico.

\section{Literatura citada}

Afonso, A.S., Medeiros, A.S., Silva, C., Nunes, R.S., Rodrigues, G.A., Menezes, L.F.T \& Conde, M.M.S. 2007. Florística da vegetação arbustiva aberta. Revista Brasileira de Biociências 5: 450-452.

APG [= Angiosperm Phylogeny Group] III. 2009. An update of the Angiosperm Phylogeny Group classification for the orders and families of flowering plants: APG III. Botanical Journal of the Linnean Society 161: 105-121.

Barroso, G.M., Morim, M.P., Peixoto, A.L. \& Ichaso, C.L.F. 1999. Frutos e sementes, morfologia aplicada à sistemática de dicotiledôneas. UFV, Viçosa. 
Baumgratz, J.F.A., Coelho, M.A.N., Peixoto, A.L., Mynssen, C.M., Bediaga, B.E.H., Costa, D.P., Dalcin, E., Guimarães, E.F., Martinell, G., Silva, D.S.P., Sylvestre, L.S., Freitas, M.F., Morim, M.P. \& Forzza, R.C. 2014. Catálogo das Espécies de Plantas Vasculares e Briófitas do Estado do Rio de Janeiro. Instituto de Pesquisas Jardim Botânico do Rio de Janeiro. Disponível em http://florariojaneiro.jbrj.gov. br/ (acesso em 19-IX-2015).

Borg, A.J., McDade, L.A. \& Schönenberger, J. 2008. Molecular Phylogenetics and Morphological Evolution of Thunbergioideae (Acanthaceae). Taxon 57: 811-822.

Braga, M.R., Vizentin-Bugoni, J. \& Rui, A.M. 2010. Comportamento de Defesa de Recursos Florais de Justicia brasiliana Roth (Acanthaceae) por Beija-Flores no Sul do Brasil. XIX Congresso de Iniciação Científica/ II Mostra Científica/XII Encontro de Pós-Graduação da Universidade Federal de Pelotas. pp. 1-4.

Braz, D.M., Veirira, M.R. \& Carvalho-Okano, R.M. 2000 Aspectos reprodutivos de espécies de Acanthaceae Juss. de um fragmento florestal do Município de Viçosa, MG. Revista Ceres 47: 229-239.

Braz, D.M., Carvalho-Okano, R.M. \& Kameyama, C. 2002. Acanthaceae da Reserva Florestal Mata do Paraíso, Viçosa, Minas Gerais. Revista Brasileira de Botânica 25: 495-504.

Braz, D.M. \& Monteiro, R. 2006. Novas espécies de Staurogyne Wall. (Acanthaceae) para o Brasil. Revista Brasileira de Botânica 29: 579-586.

Conselho Nacional do Meio Ambiente. 2012. Resolução CONAMA-453, de 02-X-2012. Diário Oficial da União, 03/10/2012, Seção 1, pág. 83. Disponível em http:// www.mma.gov.br/port/conama/res/res12/Resol453.pdf. (acesso em 17-IX-2015).

Conde, M.S.C., Lima, H.R.P. \& Peixoto, A.L. 2005. Aspectos florísticos e vegetacionais da Marambaia, Rio de Janeiro, Brasil. In: L.F.T. Menezes, A.L. Peixoto, \& D.S.D. Araújo (eds.). História Natural da Marambaia. EDUR, Seropédica, pp. 133-168.

Corrêa, N.M. \& Freire, G.V. 2010. Anacardiaceae R. Br. e Meliaceae Juss. da Marambaia, RJ. Anais da XX Jornada de Iniciação Científica da Universidade Federal Rural do Rio de Janeiro, pp. 1-3.

Côrtes, A.L.A., Daniel, T.F. \& Rapini, A. 2016. Taxonomic revision of the genus Schaueria (Acanthaceae). Plant Systematic and Evolution 302: 819-851.

Côrtes, A.L.A. \& Rapini, A. 2011. Four new species of Justicia (Acanthaceae) from the Caatinga biome of Bahia, Brazil. Kew Bulletin 66: 453-461.

Côrtes, A.L.A. \& Rapini, A. 2013. Justicieae (Acanthaceae) do Semiárido do Estado da Bahia, Brasil. Hoehnea 40: 253-292.

Daniel, T.F. \& McDade, L.A. 2014. Nelsonioideae (Lamiales: Acanthaceae): Revision of Genera and Catalog of Species. Aliso 32: 1-45.
Ezcurra, C. 2002. El género Justicia (Acanthaceae) en Sudamérica Austral. Annals of the Missouri Botanical Garden 89: 225-280.

Ezcurra, C. 1993. Systematics of Ruellia (Acanthaceae) in Southern South America. Annals of the Missouri Botanical Garden 80: 784-845.

Faria, R.R. \& Araújo, A.C. 2010 Pollination ecology of Ruellia angustiflora (Ness) Lindau ex Rambo (Acanthaceae) in the Serra da Bodoquena, Mato Grosso do Sul, Brazil. Flora 205: 106-111.

Ferreira M.C. \& Consolaro, H. 2013. Phenology and pollination and dispersal syndromes of Understory species in an urban forest remnant in central Brazil. Bioscience Journal 29: 1708-1720.

Góes, M.H.B., Silva, J.X, Rodrigues, A.F. Cavalcante, M.S.G., Roncaratti, H. Cravo, C.D., Menezes, L.F.T., Anjos, L.H.C., Valadares, G.S. \& Pereira, M.G. 2005. Modelo digital para a Restinga e Paleoilha da Marambaia, Rio de Janeiro. In: L.F.T. Menezes, A.L. Peixoto \& D.S.D. Araújo (eds.). História Natural da Marambaia. EDUR, Seropédica, pp. 231-284.

Graham, V.A.W. 1990. Delimitation and infra-generic classification of Justicia (Acanthaceae). Kew Bulletin 43: 551-624.

Hottz, D., Pereira-Moura, M.V.L., Gomes, M. 2007. Rubiaceae Juss. da Marambaia, Rio de Janeiro: Ixoroideae, Gardenieae. Revista Brasileira de Biociências 5: 642-644.

Indriunas, A. \& Kameyama, C. 2012. New Species of Herpetacanthus (Acanthaceae) from the Atlantic Forest and Neighboring Areas (Brazil). Systematic Botany 37: 1006-1022.

Judd, W.S., Campbell, C.S., Kellogg, E.A., Stevens, P.F. \& Donoghue, M.J. 2008. Plant systematics: a phylogenetic approach. New York, Sinauer Associates.

Kameyama, C. 1995. Flora da Serra do Cipó, Minas Gerais: Acanthaceae. Boletim Botânica Universidade de São Paulo 14:181-206.

Kameyama, C. 2008. New species, nomenclatural changes and lectotypifications in Neotropical Lepidagathis Willd. (Acanthaceae). Kew Bulletin 63: 565-581.

Kameyama, C., Cortês, A.L., Profice, S.R., Braz, D.M., Daly, D.C. 2008. Acanthaceae. In: A.M. Giulietti, J.M. C. Silva, A.R.L.P. Queiroz, M.J.G.A. (orgs.). Catálogo de Espécies de Plantas Raras do Brasil. Belo Horizonte: Conservação Internacional do Brasil, pp. 39-43.

Leonard, E.C. 1951. The Acanthaceae of Colombia I. Contributions of the United States National Herbarium 31: 1-117.

Lorenzi, H. \& Souza, H.M. 2008. Plantas ornamentais no Brasil: arbustivas, herbáceas e trepadeiras. Instituto Plantarum, Nova Odessa.

Magnaghi, E.B. \& Daniel, T.F. 2014. Three New Species of Mendoncia (Acanthaceae) from Madagascar Novon 23:187-196. 
Matias, R. \& Consolaro, H. 2014. Pollination biology of Geissomeria pubescens Nees (Acanthaceae) in a forest remnant in central Brazil. Botany 92: 215-222.

Matias, R. \& Consolaro, H. 2015. Polinização e sistema reprodutivo de Acanthaceae Juss. no Brasil: uma revisão Bioscience Journal 31: 890-907.

Mattos, C.L.V. 2005. Caracterização climática da Restinga da Marambaia. In: L.F.T. Menezes, A.L. Peixoto \& D.S.D. Araújo (eds.). História Natural da Marambaia. EDUR, Seropédica, pp. 67-120.

McDade, L.A., Daniel, T.F., Masta, S.E. \& Riley, K.M. 2000. Phylogenetic Relationships within the tribe Justicieae (Acanthaceae): evidence from molecular sequences, morphology, and citology. Annals of the Missouri Botanical Garden 87: 435-458.

McDade, L.A., Daniel, T.F., Kiel1, C.A. \& Vollesen, K. 2005. Phylogenetic relationships among Acantheae (Acanthaceae): major lineages present contrasting patterns of molecular evolution and morphological differentiation. Systematic Botany 30: 834-862.

McDade, L.A., Daniel, T.F. \& Kiel, C.A. 2008. Toward a comprehensive understanding of phylogenetic relationships among lineages of Acanthaceae s.l. (Lamiales). American Journal of Botany 95: 1136-1152.

McDade, L.A., Daniel, T.F., Kiel1, C.A. \& Borg, A.J. 2012. Phylogenetic placement, delimitation, and relationships among genera of the enigmatic Nelsonioideae (Lamiales: Acanthaceae). Taxon 61: 637-651.

Menezes, L.F.T. \& Araujo, D.S.D. 1999. Estrutura de duas formações vegetais do cordão externo da Restinga de Marambaia, RJ. Acta Botanica Brasilica 13: 233-235.

Menezes, L.F.T., Araujo, D.S. \& Nettesheim, F.C. 2010. Estrutura comunitária e amplitude ecológica do componente lenhoso de uma floresta de restinga mal drenada no sudeste do Brasil Acta Botanica Brasilica 24: 825-839.

Menezes, L.F.T. \& Araújo, D.S.D. 2005. Formações vegetais da restinga da Marambaia, Rio de Janeiro. In: L.F.T. Menezes, A.L. Peixoto, \& D.S.D. Araújo (eds.). História Natural da Marambaia. EDUR, Seropédica, pp. 67-120.

Menezes, L.F.T. Peixoto, A.L. \& Araújo, D.S.D. (eds.). 2005. História Natural da Marambaia. EDUR, Seropédica.

Migliorini, R.C.O., Junqueira, F.F. \& Manfrim, E.N. 2009. Biologia Floral e Sistemas Reprodutivos de Thunbergia grandiflora Roxb. (Acanthaceae). Anais do IX Congresso de Ecologia do Brasil, 13 a 17 de Setembro de 2009, São Lourenço, MG. pp. 1-3.

Nadia, T.L., Menezes N.L. \& Machado, I.C. 2013. Floral traits and reproduction of Avicennia schaueriana Moldenke (Acanthaceae): a generalist pollination system in the Lamiales. Plant Species Biology 28: 70-80.
Nees, C.G. 1847. Acanthaceae. In: C.F.P. Martius, Eichler, A. G. \& Urban, I. (eds.). Flora Brasiliensis, v. 9. F. Fleischer, Lipsiae, pp. 1-164.

Nettesheim, F.C., Menezes, L.F.T., Carvalho, D.C, Conde, M.M.S., Somner, G.V., Rodrigues, G.A. \& Araujo, D.S.D. 2012. Tree and shrub species of the Atlantic Forest on the slopes of Marambaia Island, Rio de Janeiro, Brazil. Biota Neotropica 12: 213-225.

Pereira, M.F.A. 1998. Biologia da polinização de duas espécies simpátricas de Acanthaceae, na região de Campinas, São Paulo. Dissertação de Mestrado, Universidade Estadual de Campinas, Campinas.

Pessôa, C.S. 2012. Ruellia L. (Acanthaceae) no Estado de Minas Gerais, Brasil. Dissertação de Mestrado, Universidade Federal de Viçosa, Viçosa.

Pimentel, R.R., Machado, S.R. \& Rocha, J.F. 2011. Estruturas secretoras de Pavonia alnifolia A.St.-Hil. (Malvaceae), uma espécie ameaçada de extinção. Rodriguésia 62: 253-262.

Pinto, D.S., Reis, L.P.S., Pimentel, R.R. \& Rocha, J.F. 2010. Diversidade morfológica de estruturas secretoras em Pseudobombax grandiflorum (Cav.) A. Robyns (Malvaceae) ocorrente na Restinga de Marambaia, RJ. Anais da XX Jornada de Iniciação Científica da Universidade Federal Rural do Rio de Janeiro, pp. 1-3.

Profice, S. R. 1997. Acanthaceae. In: M.C.M. Marques, A.S.F. Vaz, R. Marquete (orgs.). Flórula da APA Cairuçú, Parati, RJ: espécies vasculares, Série Estudos e Contribuições, v. 14. Jardim Botânico do Rio de Janeiro, Rio de Janeiro, pp. 9-23.

Profice, S.R. 1998. Acanthaceae. In: M.P.M. Lima \& R.R. Guedes-Bruni (orgs.). Reserva ecológica de Macaé de Cima, Nova Friburgo - RJ, aspectos florísticos das espécies vasculares, v. 2. Jardim Botânico do Rio de Janeiro, Rio de Janeiro, pp. 23-35.

Profice, S.R. 2013. Acanthaceae Juss. da Reserva Rio Das Pedras, Mangaratiba, RJ, Brasil. Pesquisas, Botânica 64:65-83.

Profice, S.R. \& Andreata, R.H.P. 2011. Revisão taxonômica de Aphelandra R. Br. (Acanthaceae) de corola curto-bilabiada. Pesquisas, Botânica 62:7-70.

Profice, S.R., Kameyama, C., Côrtes, A.L.A., Braz, D.M., Indriunas, A., Vilar, T., Pessoa, C., Ezcurra, C. \& Wasshausen, D. Acanthaceae. In: Lista de Espécies da Flora do Brasil. Jardim Botânico do Rio de Janeiro. Disponível em http:// floradobrasil.jbrj.gov.br/jabot/floradobrasil/ FB33 (acesso em 15-IX-2015).

Radford, A.E., Dickson, W.C., Massey, J.R. \& Bell, C.R. 1974. Vascular plant systematics. Harper and Row, New York. 
Rizzini, C.T. 1957. Flora do Itaitaia I, Acanthaceae. Rodriguésia 32: 138-150.

Roncarati, H. \& Menezes, L.F.T. 2005. Marambaia, Rio de Janeiro: origem e evolução. In: L.F.T. Menezes, A.L.Peixoto \& D.S.D. Araújo (eds.). História Natural da Marambaia. EDUR, Seropédica, pp. 15-38.

Sartin, R.D., Peixoto, J.C., Lopes, D.B. \& Paula, J.R. 2014. Flora do Bioma Cerrado: Abordagem de estudos da família Acanthaceae Juss - Espécies Ornamentais no Brasil. Fronteiras: Journal of Social, Technological and Environmental Science 3: 164-179.

Schwarzbach, A.E. \& Mcdade, L.A. 2002. Phylogenetic relationship of the mangrove family Avicenniaceae based on chloroplast and nuclear ribosomal DNA sequences. Systematic Botany 27:84-98.

Scotland, R.W. \& Vollensen, K. 2000. Classification of Acanthaceae. Kew Bulletin 55: 513-589.

Sigrist, M.R. \& Sazima, M. 2002. Ruellia brevifolia (Pohl) Ezcurra (Acanthaceae): fenologia da floração, biologia da polinização e reprodução/- Revista Brasileira de Botânica 25: 35-42.

Silva, C., Conde, M.M.S. \& Longhi-Wagner, H.M. 2012. Olyreae (Poaceae: Bambusoideae) da Marambaia, Rio de Janeiro, Brasil. Rodriguésia 63: 357-372.

Silva, M. G. 2011. Estudo taxonômico da subtribo Ruelliinae Nees (Acanthaceae) no estado do Paraná, Brasil. Dissertação de Mestrado, Universidade Federal do Paraná, Curitiba.

Somner, G.V., Carvalho, A.L. G. \& Siqueira, C.T. 2009. Sapindaceae da restinga da Marambaia, Rio de Janeiro, Brasil. Rodriguésia 60: 485-507.

Souza, M.C., Morim, M.P., Conde, M.M.S. \& Menezes, L.F.T. 2007. Subtribo Myrciinae O. Berg (Myrtaceae) na Restinga da Marambaia, RJ, Brasil. Acta Botanica Brasilica. 21: 49-63.

Stearn, W.T. 1998. Botanical Latin, 4 ed. Timber Press, Oregon.

Stevens, P.F. 2011. Angiosperm Phylogeny Website. Version 12, July 2012 [and more or less continuously updated since]." will do. Disponível em http://www. mobot.org/ MOBOT/research/APweb/ (acesso em 11-IX-2015).

Tomlinson, P.B. 1986. The botany of mangroves. Cambridge University, New York.
Tripp, E.A. 2007. Revolutionary relationships within the species-rich genus Ruellia (Acanthaceae). Systematic Biology 32: 628-649.

Tripp, E.A. \& McDade, L.A. 2014. A Rich Fossil Record Yields Calibrated Phylogeny for Acanthaceae (Lamiales) and Evidence for Marked Biases in Timing and Directionality of Intercontinental Disjunctions. Systematic Biology 63: 660-684.

Vogel, S., Machado, I.C. \& Lopes, A.V. 2004. Harpochilus neesianus and other novel cases of chiropterophily in neotropical Acanthaceae. Taxon 53: 55-60.

Wasshausen, D.C. 1990. New species of Stenandrium (Acanthaceae) from the planalto of Brazil. Brittonia 42: 1-6.

Wasshausen, D. 1992. Notes on Acanthaceae from Pico das Almas, Bahia, Brazil. Kew Bulletin 48: 117-20.

Wasshausen, D.C. 1995. Acanthaceae In: J.A. Steyermark, P.E. Berry, B.K. Holst (eds.). Flora of the Venezuelan Guayana. Missouri Botanical Garden, St. Louis, pp. 335-373.

Wasshausen, D.C. 1998. Acanthaceae. In: M.F. Sales, S.J. Mayo, M.J.N. Rodal (eds.). Plantas vasculares das florestas serranas de Pernambuco; um checklist da flora ameaçada dos brejos de altitude, Pernambuco, Brasil. UFPE, Recife, pp. 44-45.

Wasshausen, D.C. \& Harvey, Y.B. 1995. Acanthaceae In: B.L. Stannard (ed.). Flora of the Pico das Almas, Chapada da Diamantina - Bahia, Brazil. Royal Botanical Garden, Kew, pp. 112-114.

Wasshausen, D.C. \& Smith, L.B. Acantáceaes. 1969. In: R. Reitz (ed.). Flora ilustrada Catarinense. Herbário Barbosa Rodrigues, Itajaí.

Wasshausen, D. \& Wood, J.R.I. 2004. Acanthaceae of Bolivia. Contributions from the United States National Herbarium 49: 1-152.

Wasshausen, D.C. 2013. New species of Aphelandra (Acanthaceae) from Peru and Ecuador. Journal of the Botanical Research Institute of Texas 7: 109-120.

Witztum, A. \& Schulgasser, K. 1995. The Mechanics of Seed Expulsion in Acanthaceae. Journal of Theoretical Biology 176: 531-542.

Wood, J.R.I. 2012. Two new species of Acanthaceae from Bolivia. Kew Bulletin 67: 257-262. 